\title{
Modelling of friction stir welding of DH36 steel
}

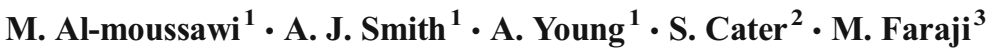

Received: 8 December 2016 / Accepted: 7 February 2017 / Published online: 24 February 2017

(C) The Author(s) 2017. This article is published with open access at Springerlink.com

\begin{abstract}
A 3-D computational fluid dynamics (CFD) model was developed to simulate the friction stir welding of $6-\mathrm{mm}$ plates of DH36 steel in an Eulerian steady-state framework. The viscosity of steel plate was represented as a nonNewtonian fluid using a flow stress function. The PCBN-WRe hybrid tool was modelled in a fully sticking condition with the cooling system effectively represented as a negative heat flux. The model predicted the temperature distribution in the stirred zone (SZ) for six welding speeds including low, intermediate and high welding speeds. The results showed higher asymmetry in temperature for high welding speeds. Thermocouple data for the high welding speed sample showed good agreement with the CFD model result. The CFD model results were also validated and compared against previous work carried out on the same steel grade. The CFD model also predicted defects such as wormholes and voids which occurred mainly on the advancing side and are originated due to the local pressure distribution between the advancing and retreating sides. These defects were found to be mainly coming from the lack in material flow which resulted from a stagnant zone formation especially at high traverse speeds. Shear stress on the tool surface was found to increase with increasing tool traverse speed. To produce a "sound" weld, the model showed that the welding speed should remain between 100 and $350 \mathrm{~mm} / \mathrm{min}$. Moreover, to prevent local melting, the maximum tool's rotational speed should not exceed 550 RPM.
\end{abstract}

M. Al-moussawi

b1045691@my.shu.ac.uk

MERI, Sheffield Hallam University, Sheffield, UK

TWI, Rotherham, UK

3 Coventry University, Coventry, UK
Keywords Friction stir welding (FSW) - Computational fluid dynamics (CFD) $\cdot$ DH36 · Weld defects

\section{Introduction}

Friction stir welding (FSW) is a solid state joining method in which the base metals do not melt. Its advantages compared to conventional welding methods include producing welds with higher integrity, minimum induced distortion and low residual stress. FSW is used largely for aluminium alloys, but recent developments have focused on higher temperature parent materials such as steel. Modelling of friction stir welding, particularly for high-temperature alloys, is a challenge due to the cost and complexity of the analysis. It is a process that includes material flow, phase change, sticking/slipping and complex heat exchange between the tool and workpiece. A review of numerical analysis of FSW is available in [1] He et al. Many studies have been carried out on FSW modelling of aluminium alloys; however, FSW modelling of steel is still limited. Nandan et al. [2] used a 3D numerical analysis to simulate heat transfer and material flow of mild steel during FSW. In their work, the viscosity was calculated from previous extrusion work where the range in which steel can experience flow was rated from 0.1 to 9.9 MPa.s. Heat was mainly generated from viscose dissipation and frictional sliding in the contact region between the tool and the workpiece and was controlled by a spatial sticking-sliding parameter based on the tool radius. There has also been extensive work done on modelling of DH36 mild steel carried by Toumpis et al. [3]. In their model, the viscoplastic thermo-mechanical behaviour was characterised experimentally by a hot compression test. They established a 3D thermo-fluid model to simulate the material flow, strain-rate and temperature distribution. Micallef et al. [4] carried out work on CFD modelling and calculating the heat flux of FSW DH36 6-mm plates by assuming full sticking conditions 
at the tool shoulder/workpiece and that the heat is generated by plastic deformation and shearing. The effects of different welding conditions including slow, intermediate and fast rotational traverse FSW speeds on stir zone (SZ) size and heat generated was studied. They found that the total heat generation for various welding conditions can be correlated with the tools radial and angular location. It is apparent that previous models are insufficient to predict defects such as wormholes and voids which are cavities or cracks below the weld surface caused by abnormal material flow during welding. These defects severely weaken the mechanical properties of the welded joints [5]. Defects are found in FSW of DH36 steel especially at high welding speeds [6]. They are also associated with fractures in both tensile [7] and fatigue tests performed on DH36 steel plates [7, 8]. These defectrelated failures highlight the need for the ability to predict the formation of sound welds using numerical modelling. There is also limited work on the FSW of steel to predict the stir zone (SZ) and high asymmetry between advancing and retreating sides especially for high welding speeds. Few people have succeeded in predicting the size, shape and position of the SZ using numerical analysis. Micallef et al. [4] tried to predict the SZ by determining the velocity of stirring which can represent the transition between stir and no stir. However, because there is no certain value of the stirring velocity, this method can contain many errors. The present work models the FSW of DH36 steel by implementing a coupled thermo-mechanical flow analysis in a research Computational Fluid Dynamic CFD code ANSYS FLUENT. It uses a steady-state analysis with a Eulerian framework in which the tool/workpiece interfaces are in the fully sticking condition. In the model rotational and traverse speeds were effectively applied and the torque on the tool shoulder was monitored. The temperature field, relative velocity, strain-rate, shear stress on the tool surface, material flow and pressure distribution were determined by solving the $3 \mathrm{D}$ energy, momentum and conservation of mass equations. The model aims mainly to predict the SZ and also the suitable rotational and traverse speeds required to obtain sound weld joints. The model is validated by comparing the temperature results with thermocouples readings of a FSW sample prepared and welded at rotational and traverse speeds of $550 \mathrm{RPM}$ and $400 \mathrm{~mm} / \mathrm{min}$, respectively. Metallographic examination was also carried out on the sample taken in order to compare the actual width of the heat-affected zone (HAZ) and stir zone with the CFD model predictions.

\section{Experimental method}

\subsection{Materials}

Eight samples of friction-stir welded DH36 steel plate with dimensions of $500 \times 400 \times 6 \mathrm{~mm}$ (in length, width and thickness, respectively) were provided by The Welding Institute (TWI). The sample had been welded using a hybrid Poly Crystalline Boron Nitride (PCBN)WRe tool using high rotational welding speed of 550 RPM and a traverse speed of $400 \mathrm{~mm} / \mathrm{min}$. Three thermocouples had been fixed at the plate bottom in the steadystate region of the weld as shown in Fig. 1a. The chemical composition of the DH36 steel used for this study is given in Table 1. This information is provided by the manufacturer, Masteel UK Ltd. Furthermore the thermal properties (specific heat and thermal conductivity) of DH36, adopted from previous work carried out on low carbon manganese steel, are given as a function of temperature as follows [9]:

$k=23.16+51.96 \cdot e^{-2.03 T / 1000}$

$C p=689.2+46.2 \cdot e^{3.78 T / 1000} \quad$ for $\mathrm{T}<700^{\circ} \mathrm{C}$

$C p=207.9+294.4 \cdot e^{1.41 T / 1000} \quad$ for $\mathrm{T}>700^{\circ} \mathrm{C}$

$\rho=7850 \mathrm{Kg} / \mathrm{m}^{3}$

where $k, C_{P}$ and $\rho$ are thermal conductivity, the specific heat and density, respectively.

The diameter of tool shoulder (made of PCBN-WRe) and the pin base were 25 and $10 \mathrm{~mm}$, respectively with the pin base length of $5.7 \mathrm{~mm}$. The tool shank was made of tungsten carbide (WC) and both shoulder and shank were surrounded by a collar made of $\mathrm{Ni}-\mathrm{Cr}$ as shown in Fig.1b. The thermal properties for the PCBN hybrid tool are given in Table 2 [10, 11].

The eight sets of welding parameters used to produce the welds that were provided by TWI are given in Table 3 . These values were taken directly from the TWI-FSW welding machine and were used to compare with the data produced form the CFD model.
Fig. 1 a Plate (W8) showing thermocouples location adjacent to the weld. b The PCBN FSW

Tool and equivalent $\mathrm{CAD}$ model

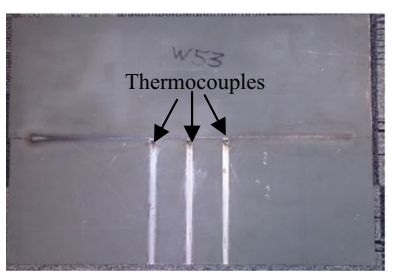

(a)

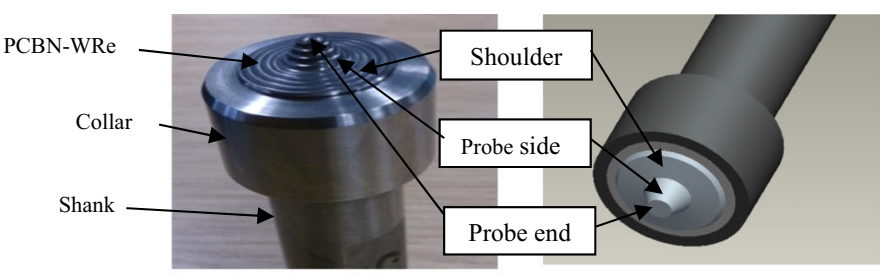

(b) 
Table 1 Chemical composition of DH36 steel provided by Masteel UK Ltd

\begin{tabular}{lllllllllllll}
\hline $\mathrm{C}$ & $\mathrm{Si}$ & $\mathrm{Mn}$ & $\mathrm{P}$ & $\mathrm{S}$ & $\mathrm{Al}$ & $\mathrm{Nb}$ & $\mathrm{V}$ & $\mathrm{Ti}$ & $\mathrm{Cu}$ & $\mathrm{Cr}$ & $\mathrm{Ni}$ & $\mathrm{Mo}$ \\
\hline 0.16 & 0.15 & 1.2 & 0.01 & 0.005 & 0.043 & 0.02 & 0.002 & 0.001 & 0.029 & 0.015 & 0.014 & 0.002 \\
\hline
\end{tabular}

\subsection{The geometry used to model the tooling and workpiece}

Due to the complexity associated with modelling the friction stir welding tool with a threaded pin, a conical shape with a smooth pin surface (without threads) was used. The designed area for the tool without threads had to be equal to the actual area with threads; therefore, the exact surface area of the tool was measured using the infinite focus microscope (IFM), and these dimensions were used to model the tool in FEM. Figure $1 \mathrm{~b}$ shows the designed tool used for the modelling versus the actual tool. The calculated surface area of the tool using the infinite focus microscopy (IFM) technique, were as follows: $A_{\text {shoulder }}=1499.2 \mathrm{~mm}^{2}, A_{\text {probe_side }}=373.2 \mathrm{~mm}^{2}$, $\mathrm{A}_{\text {probe_end }}=50.3 \mathrm{~mm}^{2}$.

The plate was designated as a disc centred on the tool rotational axis (Eulerian frame work) with a $200 \mathrm{~mm}$ diameter and $6 \mathrm{~mm}$ thickness. This is because the heat affected region in FSW is very small compared to the whole length of the workpiece [3, 12-14]. The tool and the plate were considered in the fully sticking condition. To make the model more robust, a thermal convection coefficient with high values (1000$2000 \mathrm{~W} / \mathrm{m}^{2} . \mathrm{K}$ ) was applied on the bottom surface of the plate instead of representing the backing plate and the anvil [4].

\section{The mathematical model}

In the current model, the following assumptions were made:

Material flow The mass flow was considered to be for a nonNewtonian viscoplastic material (laminar flow) whose values of viscosity were assumed to vary between a minimum and maximum experimental value, taken from a previous FSW study of mild steel [2]. The viscosity varied with strain rate and temperature. The heat generated in the contact region was mainly from viscous heating. The viscous dissipation (heat generated by the mechanical action) is also included.

Framework A Eulerian framework was applied and the tool was considered to be under "fully sticking condition" as shown in Fig. 2a. Previous work by Schmidt et al. [15] and
Atharifar et al. [12] showed experimentally that sticking conditions are closer to the real contact situation between the tool and workpiece. Cox et al. [16] carried out a CFD model on FSW and assumed pure sticking conditions at the tool/workpiece contact area. In the current model the connection between the tool and the plate was achieved by treating the domain geometry as a single part. The interior material of the plate was allowed to move by assigning an inlet velocity at one side. The other side of the plate was assigned with zero constant pressure to ensure there was no reverse flow at that side [17]. All plate walls were assumed to move with the same speed of the interior (no slip conditions) with zero shear stress at the walls. The normal velocity of the top and bottom of the plate was constrained to prevent outflow. Frictional heating was not included due to fully sticking conditions.

Material of the workpiece and tool Material properties of steel plate represented as a function of temperature, as well as the hybrid PCBN tool parts (including the collar and shank) with their properties were included.

Meshing of the model The mesh quality was very high to deliver low skewness, low aspect ratio and high orthogonality. Moreover, very fine tetrahedral mesh was used in the tool/plate contact surface to capture the high changes in velocity, temperature, strain rate and other changing characteristics of the physical properties of steel (Fig. 2b).

Cooling system of the tool The cooling system for the tool parts was included and was represented as a negative heat flux. In previous work, on the same materials (workpiece of DH36 and PCBN tool) [3] the cooling system was implemented under heat convection conditions on the side of the shank by applying a heat convection coefficient. Given that the maximum temperature on the tool cannot be measured with high precision, the calculated value of heat convection coefficient will not be accurate. Hence, using a negative heat flux on the tool surface seems to be more convenient. The loss of heat from the workpiece was represented by the application of a heat transfer coefficient on the top and bottom walls of the workpiece.
Table 2 Thermal properties of the PCBN tool $[10,11]$

\begin{tabular}{lclcc}
\hline Tool part & $\mathrm{k}\left(\mathrm{W} \cdot \mathrm{m}^{-1} \cdot \mathrm{K}^{-1}\right)$ & $\mathrm{Cp}\left(\mathrm{J} \cdot \mathrm{Kg}^{-1} \cdot \mathrm{K}^{-1}\right)$ & $\rho\left(\mathrm{Kg} \cdot \mathrm{m}^{-3}\right)$ & Ref. \\
\hline Shoulder (PCBN-WRe) & 120 & 750 & 3480 & $*$ \\
Shank (WC) & 92 & 500 & 14,900 & $*$ \\
Collar & 11 & 440 & 8900 & $*$ \\
\hline
\end{tabular}


Table 3 Eight welding conditions provided by TWI and used in the CFD analysis

\begin{tabular}{llllllll}
\hline $\begin{array}{l}\text { Weld } \\
\text { No. }\end{array}$ & $\begin{array}{l}\text { Tool } \\
\text { rotational } \\
\text { speed RPM }\end{array}$ & $\begin{array}{l}\text { Traverse } \\
\text { speed } \\
\mathrm{mm} / \mathrm{min}\end{array}$ & $\begin{array}{l}\text { Rotational/ } \\
\text { Traverse } \\
\text { speeds }\end{array}$ & $\begin{array}{l}\text { average } \\
\text { spindle } \\
\text { Torque N.m }\end{array}$ & $\begin{array}{l}\text { average } \\
\text { tool } \\
\text { Torque } \\
\text { N.m }\end{array}$ & $\begin{array}{l}\text { Axial force } \\
\text { (average) } \\
\text { KN }\end{array}$ & $\begin{array}{l}\text { lateral } \\
\text { force } \\
\text { (average) } \\
\text { KN }\end{array}$ \\
\hline W1 & 160 & 100 & 1.6 & 308 & 117 & 54.47 & 6.99 \\
W2 & 200 & 100 & 2 & 278 & 105 & 57.55 & 12.8 \\
W3 & 300 & 250 & 1.2 & 237 & 90 & 59.9 & 19.39 \\
W4 & 325 & 400 & 0.8125 & 247 & 94 & 64 & 20.88 \\
W5 & 500 & 400 & 1.25 & 202 & 77 & 53.33 & 16.52 \\
W6 & 550 & 400 & 1.375 & 163 & 62 & 62.5 & 13.94 \\
W7 & 550 & 400 & 1.375 & 179 & 68 & 59 & 12.8 \\
W8 & 550 & 400 & 1.375 & 168 & 64 & 58.69 & 13.4 \\
\hline
\end{tabular}

Rotational speed of the tool Tool rotational speed ( $\mathrm{rad} / \mathrm{s})$ was effectively applied in the contact region between the tool and the workpiece. This gave the material in the contact region asymmetry from the advancing to the retreating side as the material flows from the inlet to the outlet (Fig. 2a). The values for torque under the shoulder were monitored during the solution; the stability of torque after many numbers of iteration is a sign of solution convergence. Convergence in FLUENT also occurs once the velocity and continuity residual fall below 0.001 and energy residual below $10^{-6}$. A pressure-velocity coupling algorithm was used to solve the energy and the flow equations (solving the continuity and momentum equations in a coupled manner) to effectively cover the non-linear physical model [17]. Gravitational forces were neglected here due to the very high viscous effect of the material [12]. Some of the mention assumptions have been used in previous publications for the authors [18] to model the same grade of steel with two differences -a- fully sticking conditions so the material velocity is equal to tool rotational speed -b-heat generated is totally from viscose heating instead of frictional and plastic heat source.

\subsection{The governing equations}

The continuity equation for incompressible material can be represented as [2]

$\frac{\partial u_{i}}{\partial x_{i}}=0$

$u_{i}$-is the velocity of plastic flow in index notation for $i=1,2$ and 3 which representing the Cartesian coordinate of $x, y$ and $z$ respectively.

A. Heat transfer and plastic flow equation The temperature and velocity field were solved assuming steady-state behaviour. The plastic flow in a three-dimensional Cartesian coordinates system can be represented by the momentum conservation equation in index notation with $i$ and $j=1,2$ and 3, representing $\mathrm{x}, \mathrm{y}$ and $\mathrm{z}$, respectively [2]

$\rho \frac{\partial u_{i} u_{j}}{\partial x_{i}}=-\frac{\partial p}{\partial x_{j}}+\frac{\partial}{\partial x_{i}}\left(\mu_{u} \frac{\partial u_{j}}{\partial x_{i}}+\mu_{u} \frac{\partial u_{i}}{\partial x_{j}}\right)-\rho U \frac{\partial u_{j}}{\partial x_{1}}$

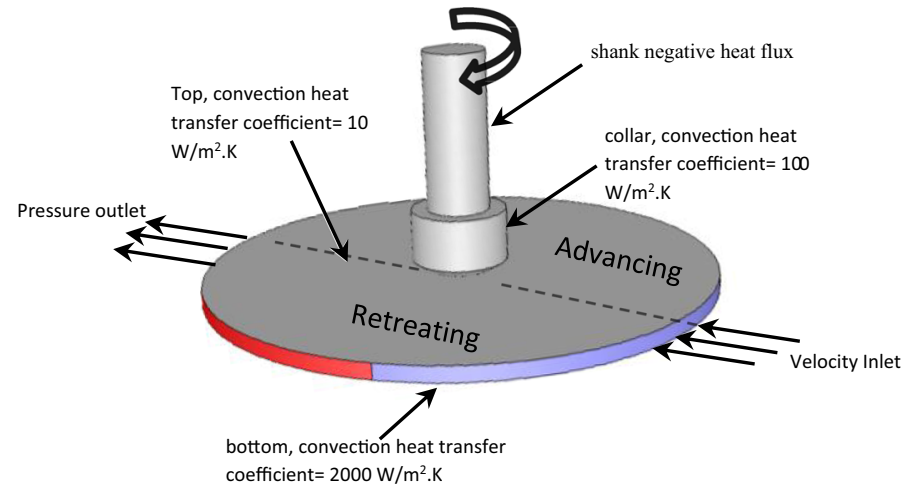

(a)

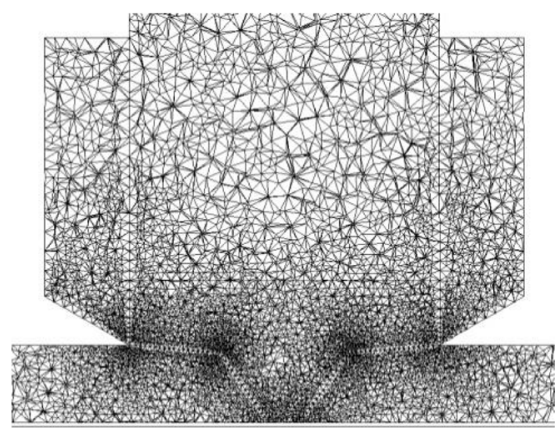

(b)

Fig. 2 a Geometry and boundary conditions. b Traverse section showing the mesh 
where $\rho, p, U$ and $\mu_{u}$ are density, pressure, welding velocity, and Non-Newtonian viscosity, respectively. Viscosity is determined using the flow stress $\left(\sigma_{f}\right)$ and the effective strain rate $(\varepsilon)$ as follows:

$\mu_{u}=\frac{\sigma_{f}}{3 \varepsilon^{\prime}}$

The flow stress in a perfectly plastic model, proposed by Sheppard and Wright [18] is:

$\sigma_{f}=\frac{1}{\alpha} \sinh ^{-1}\left[\left(\frac{Z_{n}}{A i}\right)^{\frac{1}{n}}\right]$

$n, A i, \alpha$, are material constants. Previous work on C-Mn steel showed that the parameter A can be written as a function of carbon percentage (\%C) as follow [2]:

$A_{i}=1.8 \times 10^{6}+1.74 \times 10^{8}(\% C)-6.5 \times 10^{8}(\% C)^{2}$

$\alpha$ and $n$ are temperature dependents and can be represented as:

$\alpha=1.07+1.7 \times 10^{-4} \mathrm{~T}^{-2.81 \times 10^{-7} T^{2}}$

$n=0.2+3.966 \times 10^{-4} T$

$Z_{n}$ is the Zener-Hollomon parameter which represents the temperature compensated effective strain rate as [2]:

$\left.Z_{\mathrm{n}}=\varepsilon \cdot \exp \left(\frac{Q e}{R T}\right)=A i\left[\sinh \alpha \sigma_{f}\right)\right]^{n}$

$Q e$ is the activation energy, $R$ is the gas constant. The effective strain rate can be represented as:

$\varepsilon^{\cdot}=\sqrt{\frac{2}{3} \varepsilon_{i j} \varepsilon_{i j}}$

$\varepsilon_{i j}$ - is the strain tensor and can be represented as:

$\varepsilon_{i j}=\frac{1}{2}\left(\frac{\partial u_{j}}{\partial x_{i}}+\frac{\partial u_{i}}{\partial x_{j}}\right)$

B. Heat equation Here, the Eulerian algorithm is used in which the FSW tool is represented as solid whereas the workpiece material is represented as liquid and flows through the mesh usually in steady-state solution $[2,19]$ :

$\rho C_{p} \nabla(u T)=\nabla(k \nabla T)-\rho C_{p} v_{x} \nabla T+Q_{i}+Q_{b}$

where parameters are as follows: $\rho=$ material density, $C_{p}=$ specific heat, $v_{x}=$ velocity in the X-direction, $T=$ temperature and $k$ is the thermal conductivity. $\mu_{u}=$ viscosity,$u=$ material velocity, $Q_{i}=$ Source term which is mainly coming from the heat generated in the interface between the tool and workpiece. The heat generated in this model is based on viscosity dissipation and the material flow due to the tool rotation forming shear layers. The viscous heating $\left(\mu_{u}\left(\nabla^{2} u\right)\right)$ was assumed to be the main source of heat generation in this work. $Q_{b}=$ heat generated due to plastic deformation away from the interface. Some distance away from the tool-workpiece interface, the material experiences plastic deformation due to tool rotation which has an impact on the adjacent material. This deformation produces insignificant heat (less than 5\%) [2] so it will be neglected in this work.

\subsection{Parent material movement and associated velocity}

A specified node in the simulation, shown in Fig. 3, is assumed in which as the tool rotates and the material moves through the mesh, the node is transferred from location 1 to 2 where its parametric coordinates can be represented as follows:

$Z=U t+r\left(\cos \left(\theta_{2}\right)-\cos \left(\theta_{1}\right)\right)$

$X=r\left(\sin \left(\theta_{2}\right)-\sin \left(\theta_{1}\right)\right)$

And by deriving the coordinate equations (Eqs. 16 and 17), the velocities ( $\mathrm{u}$ and $\mathrm{v}$ ) in $\mathrm{x}$ and $\mathrm{z}$ directions can be obtained as [20]:

$w=d Z / d t=U-\mathrm{r} \omega \sin \theta$

$u=d X / d t=\mathrm{r} \omega \cos \theta$

Due to representing of the pin without threads in the current simulation and also the material sticking conditions in the contact region, the vertical velocity (Y-direction) was negligible and the velocity magnitude is represented as:

$V=\sqrt{u^{2}+w^{2}}=\sqrt{r^{2} \omega^{2}-(2 \mathrm{r} \omega \mathrm{U} \sin \theta)+U^{2}}$

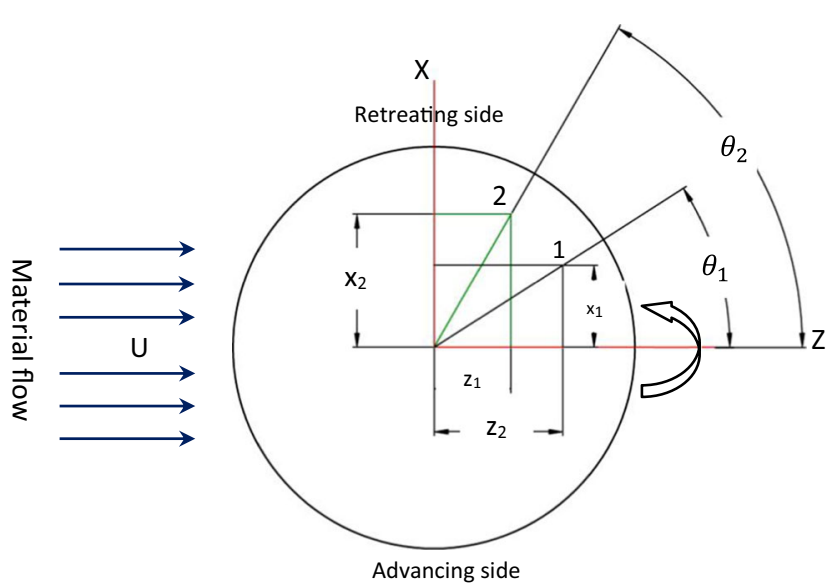

Fig. 3 The material flow around the tool in FSW (steady state), material is moved from point 1 to point 2 
A previous model depending on sticking/sliding has included the vertical drag of the material [18].

\subsection{Boundary conditions}

The temperature of the workpiece was set at room temperature $\left(25^{\circ} \mathrm{C}\right)$. The heat loss from the tool-workpiece can be divided as:

A. Heat partition between the tool and the workpiece Tool parts are expected to gain heat more than the workpiece during FSW due to the low thermal conductivity of DH36 steel (as received from the manufacturer $=45-55 \mathrm{~W} / \mathrm{m} . \mathrm{K}$ ) compared to the tool types (PCBN) which is about three times that of steel. The partition of heat between tool and workpiece has been calculated by other researchers $[2,21]$ as follows:

$$
f=\frac{J_{W P}}{J_{W P}+J_{T L}}=\frac{\sqrt{\left(k \rho C_{p}\right)_{W P}}}{\sqrt{\left(k \rho C_{p}\right)_{W P}}+\sqrt{\left(k \rho C_{p}\right)_{T L}}}
$$

where WP and TL denote the workpiece and the tool; and $f$ and $J$ are the fraction of heat entering the workpiece and generated heat respectively. So the heat transfer at the tool/shoulder interface was determined as follow:

$\left.k \frac{\partial T}{\partial z}\right]_{\text {top }}=\frac{\sqrt{\left(k \rho C_{p}\right)_{W P}}}{\sqrt{\left(k \rho C_{p}\right)_{W P}}+\sqrt{\left(k \rho C_{p}\right)_{T L}}} Q_{i}$

The heat fraction transferring into the workpiece, $\mathrm{f}$, was estimated between 0.4 and 0.45 for welding using a tungsten based tool and workpieces of mild or stainless steel $304 \mathrm{~L}$. However, for welding PCBN tool with a cooling system as in this work, Eq. 22 cannot accurately represent the heat fraction between the tool and the workpiece. The reasons being that the PCBN tool is a hybrid tool which consists of four different materials with different thermal properties. Also the presence of the cooling system and gas shield will affect this heat fraction. Subrata and Phaniraj [22] showed that Eq. 22 is only valid when the tool and plate are considered as an infinite heat sink with no effects of heat flow from the air boundary of the tool and they found that the heat partitioned to the tool is less than calculated from Eq. 22. Therefore, in the present simulation the tool was represented in the geometry to estimate the heat fraction numerically. Heat removed from the tool during the FSW process due to the cooling system can be calculated from the following Eq. [23]:

$Q_{\text {cooling }}=\dot{m} C_{p} \Delta T$

where $\dot{m}$ is the flow rate of the coolant (in L/min for liquid and $\mathrm{m}^{3} / \mathrm{h}$ for gas). $\Delta \mathrm{T}$ is the difference between inlet and outlet coolant temperature. Table 4 shows the various coolants types for the shank and collar parts of the tool with their associated characteristics. The calculated heat has been divided on the exposed area and then represented on the tool part as a negative heat flux.

Using a range of flow rates may dramatically affect the values of outlet temperature and in turn the heat flux values. However, in the current work, an average value was calculated and used.

B. Heat losses from the workpiece top surface To define the boundary condition for heat transfer between the top surface of the workpiece and the surroundings (away from the shoulder), convection and radiation in heat transfer can be considered which can be represented as: [2]

$q=h\left(T-T_{\circ}\right)+\epsilon \sigma\left(T^{4}-T_{\circ}^{4}\right)$

where $T_{o}$ is the room temperature $\left(25^{\circ} \mathrm{C}\right), \varepsilon$ is the emissivity of the plate surface, $\sigma$ is the Stefan-Boltzmann constant $\left(5.67 \times 10^{-8} \mathrm{~W} \mathrm{~m}^{-2} \mathrm{~K}^{-4}\right)$, and $\mathrm{h}$ is the convection coefficient $\left(\mathrm{W} \mathrm{m}^{-2} \cdot \mathrm{K}^{-1}\right)$. In the current model the radiation equation was neglected as it will add more complexity to the case. As a first approximation the radiation effect was accommodated by increasing the value of heat convection coefficient around the tool [4].

C-heat loss from the workpiece bottom surface The lower surface of the plate is in contact with the steel backing plates (usually mild and $\mathrm{O}_{1}$ steel grades) and the anvil. Previous workers [24] have suggested representing the influence of

Table 4 The various coolants types for shank and collar parts of the tool with associated characteristics [10]

\begin{tabular}{cccccccc}
\hline Coolant & Flow rate $m$ & $\begin{array}{c}\text { Specific } \\
\text { heat } \mathrm{Cp}\end{array}$ & $\begin{array}{l}\text { Inlet Coolant } \\
\text { Temperature }\left({ }^{\circ} \mathrm{C}\right)\end{array}$ & $\begin{array}{l}\text { Outlet Coolant } \\
\text { Temperature }\left({ }^{\circ} \mathrm{C}\right)\end{array}$ & $\begin{array}{l}\text { Average } \\
\text { heat }(\mathrm{W})\end{array}$ & $\begin{array}{l}\text { Tool Surface Area } \\
\text { exposed to fluid }\left(\mathrm{mm}^{2}\right)\end{array}$ & $\begin{array}{l}\text { Average heat } \\
\text { flux }\left(\mathrm{W} / \mathrm{mm}^{2}\right)\end{array}$ \\
\hline $\begin{array}{r}50 \% \text { Ethanol glygol } \\
+50 \% \text { distil water }\end{array}$ & $5.3-13.3 \mathrm{~L} / \mathrm{min}$ & $\begin{array}{c}3.41 \\
\mathrm{KJ} / \mathrm{Kg} .\end{array}$ & 15 & 17 & 602 & 4720 & 0.217 \\
Air & $5.7 \mathrm{~m}^{3} / \mathrm{h}$ & $\begin{array}{c}1.2 \\
{ }^{\circ} \mathrm{C} \\
\mathrm{KJ} / \mathrm{m}^{3} . \\
{ }^{\circ} \mathrm{C}\end{array}$ & $15-20$ & $100-125$ & 142.5 & 2760.67 & 0.0688 \\
\hline
\end{tabular}


backing plates by a convection heat condition with higher coefficient of heat transfer values, ranging from 500 to $2000 \mathrm{~W} / \mathrm{m}^{2} . \mathrm{K}$. The exact value of the heat coefficient applied on the bottom surface is not accurately known and the data related for this simulation is limited. However, adapting the value of $2000 \mathrm{~W} \cdot \mathrm{m}^{-2} \cdot \mathrm{K}^{-1}$ was found to give a reasonable distribution of temperature at the plate bottom. All governing equations and boundary conditions were carried out in Fluent software which is capable of solving the $3 \mathrm{D}$ equations of velocity and momentum.

\section{Results and discussion}

In all images, the advancing side of the weld is on the left hand side.

\subsection{Torque}

In this model, the torque is calculated under the shoulder of the tool as it is found by Long et al. [25] that the torque from the shoulder represents the major part of the total torque which, in turn, comes mainly from the viscous and local pressure forces. Table 5 gives the values for the maximum temperature and torque obtained through the proposed numerical model for the 8 weld cases. Comparing Tables 3 and 5 shows that the values for numerically calculated torque are within the range of the torque experimentally calculated by the FSW machine mentioned in Table 3. Given that very limited numbers of eight samples were welded using just six rotational and traverse speed variations; a clear relationship cannot be established between the welding speed and the torque. However, comparing two sets of data presented in Table 4 (W1 and W2 and W4 through W8) show that the torque decreases with an increase in tool rotational speed at a constant traverse speed. This result is in accordance with the results found in [25] for welding aluminium alloys. They have found, through simulation validated by experimental data, that an increase in rotating speed decreases the torque until reaching a relatively constant limit that is subject to only slight change with increasing tool rotational speed. They argued that the torque depends on the contact shear stress between the tool and workpiece, and thus by increasing the tool rotational speed, the temperature of the welded region increased, causing a decrease in the contact shear stress and thus the torque. The relationship between torque and flow shear stress is described in Eq. 25 [25]. Atharifar et al. [12] also reported a decrease in torque with increasing tool rotational speed and decreasing travers speed as a result of a low viscosity field resulting from an accumulation in thermal energy. From this discussion, it is expected that torque increases with increasing traverse speed at a constant tool rotational speed. However, the welds provided for the current study did not include constant tool rotational speeds with different traverse speeds but a previous study on FSW of stainless steel has reported such torque increase [26]. The axial and lateral forces in this work will not be discussed here because of the complexity and also due to the fact that the FSW machine was "position" controlled which means the tool was fixed at a constant vertical distance from the workpiece irrespective of the forces acting on the tool [3]. Table 3 includes three experimental welding cases with the same rotational/travers speeds (W6, W7 and W8) but shows different axial/lateral forces. The CFD modelling can only give constant axial/lateral forces for fixed rotational and traverse speeds. The relationship between torque and shear flow stress is shown in eq. 25 :

$\tau=\frac{M_{\text {tool }}}{V o l_{\text {contact }}}$

where $\tau$ is the flow shear stress $\mathrm{Pa}$., $M_{\text {tool }}$ is the tool torque (N.m), Vol $_{\text {contact }}$ is the tool/workpieace contact volume $\left(\mathrm{m}^{3}\right)$.

The tool torque is calculated from the spindle motor torque measured experimentally from the PwerStir FSW machine
Table 5 Predicted values for the maximum temperature and torque obtained by the proposed numerical model for eight welded samples with different rotational and traverse speeds

\begin{tabular}{lllllll}
\hline $\begin{array}{l}\text { Weld } \\
\text { No. }\end{array}$ & $\begin{array}{l}\text { Tool } \\
\text { rotational } \\
\text { speed } \\
(\mathrm{RPM})\end{array}$ & $\begin{array}{l}\text { Traverse } \\
\text { speed } \\
(\mathrm{mm} / \mathrm{min})\end{array}$ & $\begin{array}{l}\text { Rotational/ } \\
\text { traverse } \\
\text { ratio }\end{array}$ & $\begin{array}{l}\text { Maximum } \\
\text { calculated } \\
\text { temperature }\left({ }^{\circ} \mathrm{C}\right)\end{array}$ & $\begin{array}{l}\text { Calculated CFD } \\
\text { Spindle Torque } \\
(\mathrm{N} . \mathrm{m})\end{array}$ & $\begin{array}{l}\text { Calculated } \\
\text { CFD tool } \\
\text { Torque (N.m) }\end{array}$ \\
\hline W1 & 160 & 100 & 1.6 & 938 & 290 & 110 \\
W2 & 200 & 100 & 2 & 1090 & 250 & 95 \\
W3 & 300 & 250 & 1.2 & 1150 & 234 & 89 \\
W4 & 325 & 400 & 0.81 & 1170 & 270 & 104 \\
W4 & 500 & 400 & 1.25 & 1370 & 210 & 80 \\
W6 & 550 & 400 & 1.38 & 1440 & 200 & 76 \\
W7 & 550 & 400 & 1.38 & 1440 & 200 & 76 \\
W8 & 550 & 400 & 1.38 & 1440 & 200 & 76 \\
\hline
\end{tabular}


and multiplied by the transfer ratio of conveyor as in the following eq. [27 p467]:

$M_{\text {tool }}=T R C \cdot M_{\text {spindle }}$

where $M_{\text {spindle }}$ is the motor spindle torque N.m, TRC is the transfer ratio of conveyor which is equal to 0.38 .

\subsection{Temperatures of the workpiece}

Figure 4 gives the temperature contours for the welding conditions studied for samples W1 through W8. W6 through W8 are presented in one image; they are repeated welds with the same welding rotational and traverse speeds but with different axial and lateral forces. For all cases shown in Fig. 4, the temperature is very high around the tool but the contour expands just after the contact region. This suggests that heat is moving slowly through the material because of the low thermal conductivity. They also reveal that the contours of temperature tend to be more compressed with high welding speed as shown for W4, W5 and W6-W8. This can lead to a faster cooling rate than those with a slow traverse speed. Thermal cycles of W2 and W6 as examples of low and high welding speeds are shown in Fig. 5. Time in these curves was calculated by dividing the travelling distance by the travelling speed, the travelling distance was monitored from the tool shoulder periphery towards the trailing direction. These curves of cooling rate state that despite the high tool rotational speed of sample W6 which was expected to generate a higher temperature in the tool/workpiece interface, the cooling rate was higher because of the higher traverse speed compared with W2. It is shown in Fig. 4 (W1 and W2) that using low welding speeds the temperature profile is almost distributed symmetrically around the tool radius. However, for welds with
Fig. 4 Top view of contours of temperature $\left({ }^{\circ} \mathrm{C}\right)$ for 6 different welding conditions (samples W1 to W8) (Ansys Fluent)

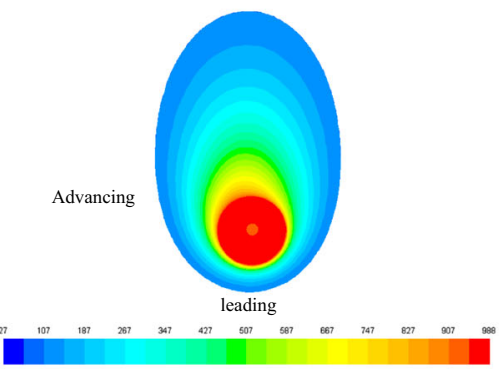

W1

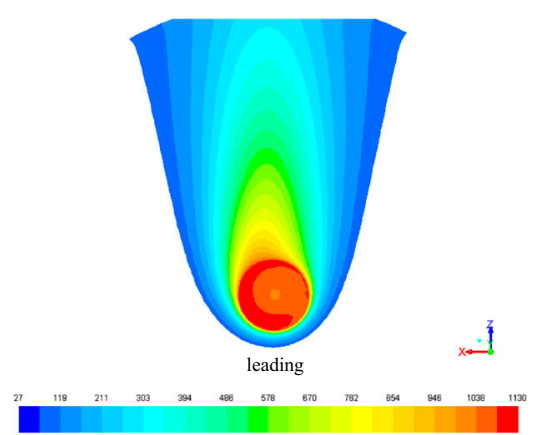

W3W4

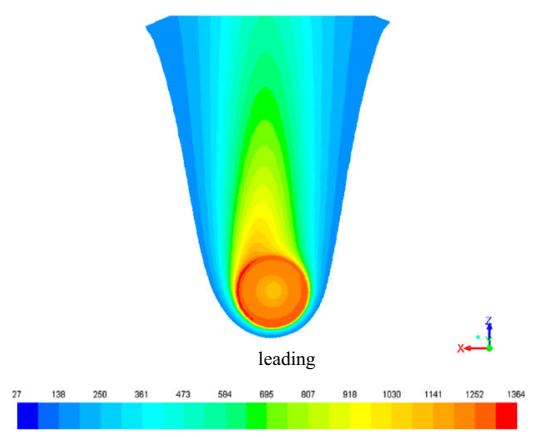

W5

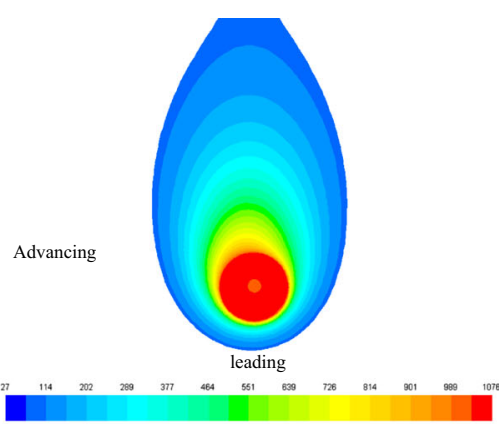

W2
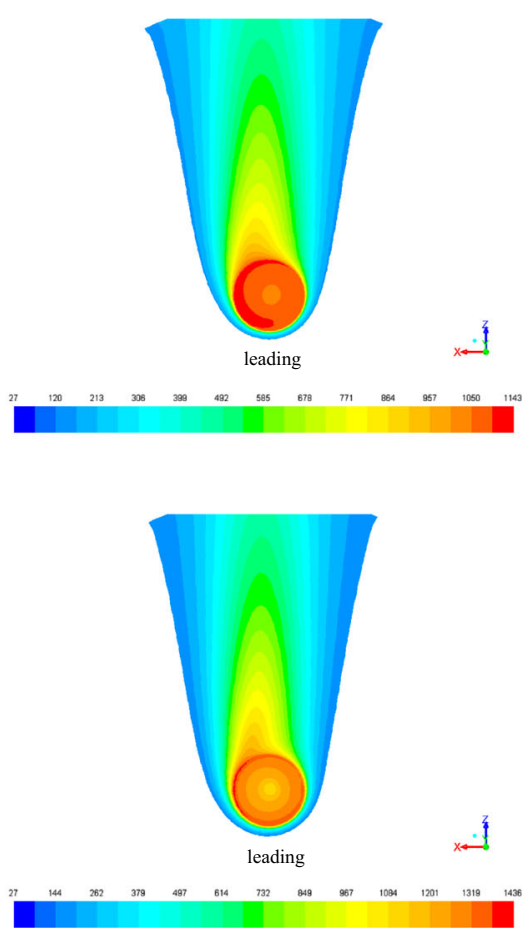

W6-W08 
Fig. 5 Cooling rate of W2 and W6, CFD results measured from the tool shoulder periphery towards the trailing direction

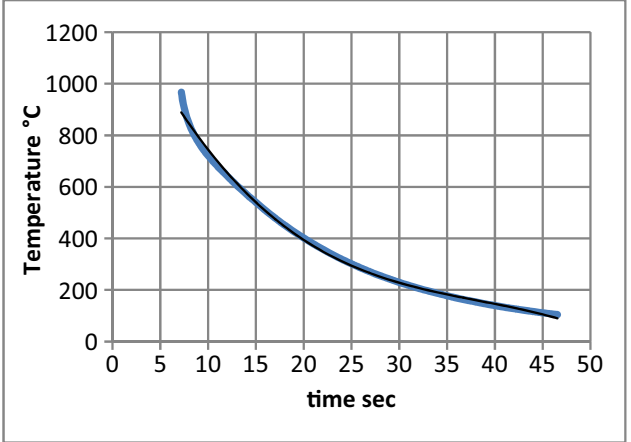

W2 200RPM $/ 100 \mathrm{~mm} / \mathrm{min}$, cooling rate $20^{\circ} \mathrm{C} / \mathrm{sec}$

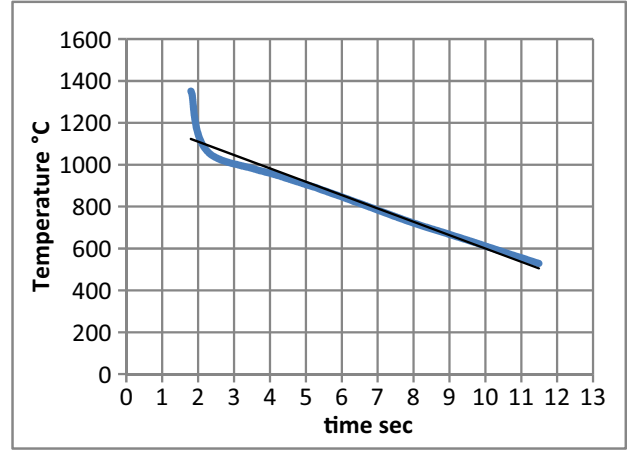

W6 550RPM $/ 400 \mathrm{~mm} / \mathrm{min}$, cooling rate $45^{\circ} \mathrm{C} / \mathrm{sec}$ intermediate and high tool speeds (Figs. 4 W3, W4 and W6) the maximum temperature was under the shoulder interface between the advancing side and the trailing edge but closer to the advancing side. This is the maximum temperature which can be expected in this location due to the material flow condition around the tool which will be discussed later in the material flow section. Similar to this finding, Fehrenbacher et al. [28] developed a measurement system for FSW of aluminium alloys and measured the temperature of the interface between the tool and the plate experimentally using thermocouples and found that the maximum temperature was at the shoulder interface in the advancing-trailing side closer to the advancing side of the welds. Micallef et al. [4] by using CFD modelling and experimental validation, found that the maximum temperature occurs on the advancing side and towards the rear of the shoulder's surface while the minimum temperature occurs in the pin region at the leading edge of the tool. Lower plastic deformation due to the lower viscosity at the front of the tool surface has been given as a reason for this minimum temperature. Darvazi et al. [21], through numerical modelling, found that the maximum temperature in FSW of stainless steel $304 \mathrm{~L}$ was in the back half of the shoulder region and towards the advancing side. They also found that there was more asymmetry in temperature under the shoulder compared to the regions away from it. Moreover, Atharifar et al. [12] proved numerically and experimentally (using thermocouple readings) that the maximum temperature in FSW of aluminium was at the advancing side. This was attributed to the high relative velocity at the advancing side causing more viscoplastic material shearing and consequently the higher heat generation through plastic deformation and viscous heating. To present the temperature distribution at the shoulder/plate interface, Fig. 6 illustrates the temperature contours for the six welding conditions undertaken in this work, the temperature colour bar are unified in one bar to enhance the contrast. As shown in Fig. 4, a maximum temperature (under the shoulder) of (1259 K)
$986{ }^{\circ} \mathrm{C}$ and $(1349 \mathrm{~K}) 1076{ }^{\circ} \mathrm{C}$ with wide contours was observed for W1 and W2, respectively. Welds with higher welding speeds (W5, W6-8) show a higher temperature of (1637 K) $1364{ }^{\circ} \mathrm{C}$ and $(1709 \mathrm{~K}) 1436{ }^{\circ} \mathrm{C}$ respectively because of the high tool rotational speed but they have narrow contours and high temperatures towards the probe sides and probe end. The result from the thermocouple temperature measured at the plate bottom of W8 are shown in Fig. 7 and are in good agreement with the CFD results. A peak temperature of $910^{\circ} \mathrm{C}$ was recorded by thermocouples at the plate bottom, while $1030{ }^{\circ} \mathrm{C}$ was the results of the CFD model. This difference in peak temperature at the plate bottom may come from the assumption of heat convection coefficient value in the CFD model which needs more experimental work to estimate the exact value of this coefficient. Asymmetry between advancing and retreating sides is increased as traverse speed increase as shown in Fig. $6 \mathrm{~W} 4, \mathrm{~W} 5$ and W6. However, it is expected to observe a smaller Heat Affected Zones (HAZ) for these samples with higher tool traverse speeds. Low welding speeds (Fig. 6 W1, W2 and W3.) showed a wider HAZ. Micallef et al. [4] reported the same effects of welding speed on the size of HAZ for the same type and thickness of steel grade. Similarly, they found that the asymmetry between advancing and retreating sides of the welds was increased for the higher welding speeds (here in W4,W5 and W6-8). This is attributed to more material being pushed under the shoulder's periphery at the advancing side. From the CFD result, it is worth noting that samples produced with high welding speeds (W6-8) can reach temperatures close to the melting point in a small local region at the advancingtrailing side (Fig. 4 W6-W8). The evidence of localised melting at the same advancing-trailing side has been reported in [28] and also in [29] for welding aluminium alloys. Colegrove and Shercliff [30] found that maximum temperature calculated from CFD modelling of aluminium at $90 \mathrm{~mm} / \mathrm{min}$ and $500 \mathrm{RPM}$ is exceeding the melting point. However, they suggested that in actual welds this 
Fig. 6 Side view, perpendicular to the welding direction, contours of temperature $\left({ }^{\circ} \mathrm{C}\right)$ for six different welding conditions (samples W1 to W6) (Ansys Fluent)

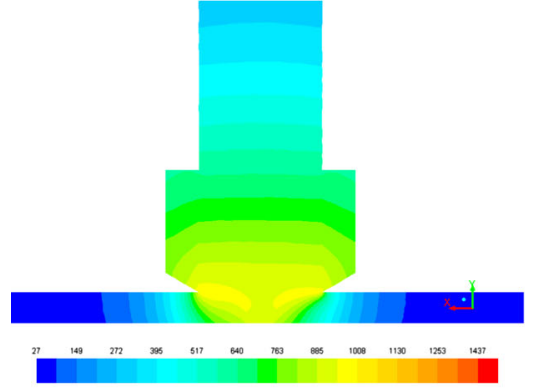

W1

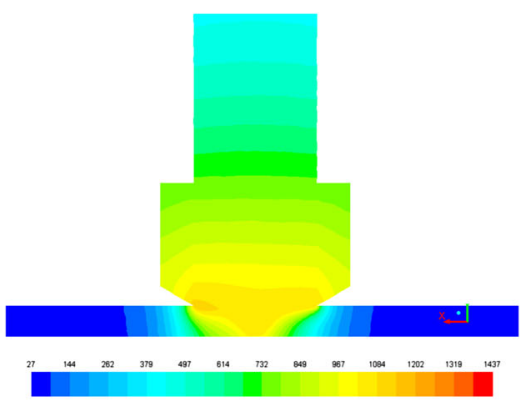

W3

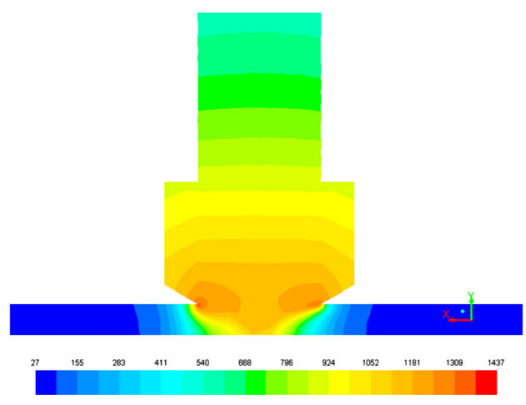

W5

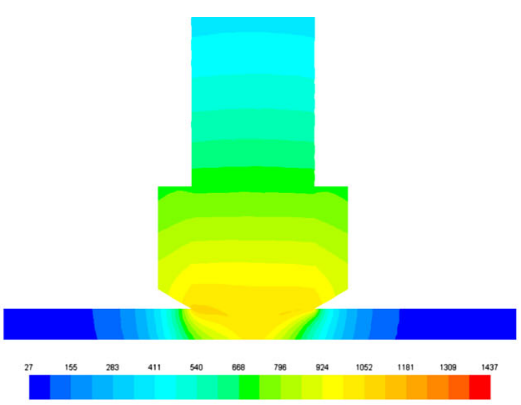

W2

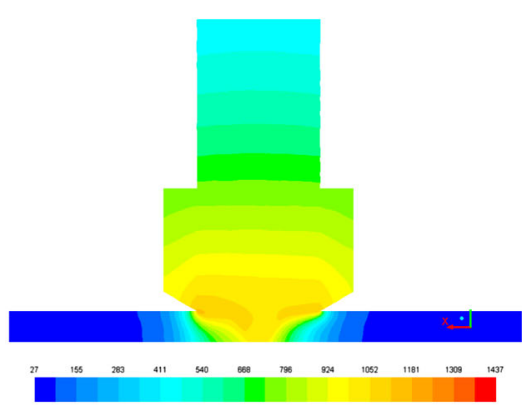

W4

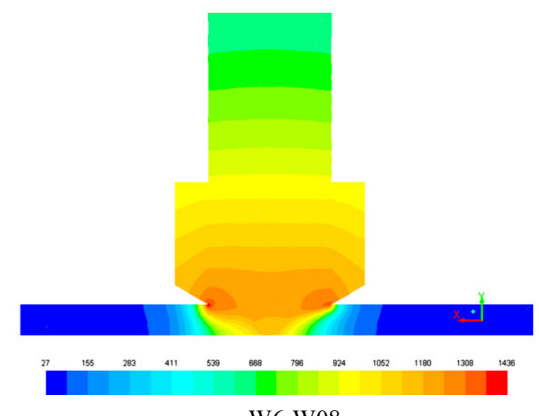

W6-W08 temperature would be lower due to two reasons; firstly in the actual weld, slip between the tool and the workpiece can occur reducing the heat input and consequently avoiding melting. Secondly, the material softens considerably at high temperatures near the solidus which reduces the heat generation and hence, the temperature. The present model suggests a higher temperature for high welding speeds close to the melting point in a very small area localised in the advancing-trailing side. This assumption is mainly coming from applying full sticking conditions which cause high deformation and material flow. Local melting is expected at lower tool rotational speeds
Fig. 7 Thermal cycle of W8, comparison of thermocouples data and CFD, model. A distance of $100 \mathrm{~mm}$ staring from the plate bottom centre towards the welding line was divided by the welding velocity in order to represent the time (15 s)

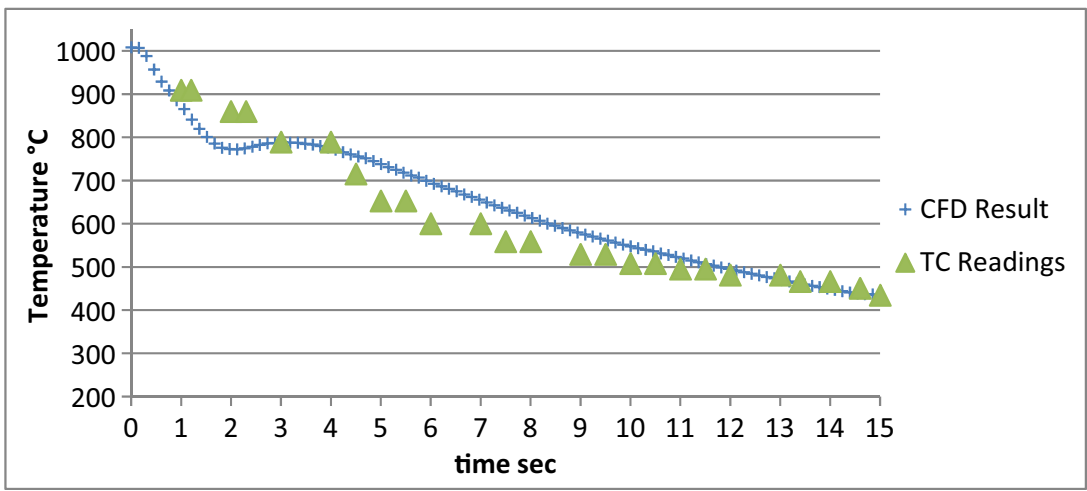


if the thermal conductivity of the workpiece is low as is the case when welding 304 stainless steel [31]. The peak temperature is expected to be lower in the case of applying the sticking/slipping conditions [18].

Comparing the maximum temperature for $\mathrm{W} 3$ and $\mathrm{W} 5$ (as shown in Fig. 6), it is evident that although their ratio of rotational to the traverse speed is nearly the same (in Table 3: 1.2 and 1.25, respectively), the maximum temperature reached at the advancing-trailing side is quite different; 1130 and $1364{ }^{\circ} \mathrm{C}(1403$ and $1737 \mathrm{~K})$, respectively. This suggests that increasing tool rotational speed has a profound effect on heat production compared to the traverse speed. Moreover, comparing W3 with W4 (Fig. 4) shows that the maximum peak temperature of both is nearly equal (1130 and $1143{ }^{\circ} \mathrm{C}(1403$ and $1416 \mathrm{~K})$, respectively); however, material at the probe-side experienced a lower temperature in W3 because of less tool rotational speed. This means that for these welds, increasing tool rotational speed from 300 to 325 RPM can give nearly the same maximum temperature despite the increase in traverse speed in W4 which led to a faster cooling rate and hence less heat input. This, consequently, resulted in a smaller temperature distribution in the tool/workpiece depth and thus a smaller HAZ is expected. Colegrove and Shercliff [30] also reported the same effect; that changing the tool rotational speed has a more significant effect on the peak temperature than a change in traverse speeds and the HAZ decrease with the increase in traverse speed. Temperature contours of the longitudinal cross section of the tool for all cases studied shown in Fig. 6 are circular and tend to bend towards the tool shank. The tool collar acts as an insulator because of its low thermal conductivity, so most of the heat was partitioned between the PCBN-WRe and shank from one side and the workpiece from another side. The Shank loses heat mainly by convection coming from the cooling system as previously described. From the contours of temperatures in Fig. 6, it can be confirmed that heat is mainly transferred by conduction through the tool parts unlike the workpiece in which heat is transferred by the material flow.

\subsection{Comparison of CFD result with experimental and other work}

Figure 8 compares the stirred zone and HAZ obtained from modelling with the experimental macrograph of W8. It is shown that the width of the HAZ is varied in the range of temperatures between $(1273-1373 \mathrm{~K}) 1000-1100{ }^{\circ} \mathrm{C}$ but not below $(1173 \mathrm{~K}) 900{ }^{\circ} \mathrm{C}$. There is no specific rule to calculate the size of this zone as a function of tool speeds; hence the shape of SZ is not easy to determine from numerical CFD simulation. In a previous work [4] the SZ geometry was studied using CFD to understand how it varies with the operating conditions of traverse and tool rotational speeds. The relative velocity was considered to represent the transition between stir and no stir. However, the exact value of velocity of stir is not given. In the current model, the whole stirred and heataffected zones are compared with the temperature contour as shown in Fig. 8 for the steady-state case and it is evident that HAZ is located in the range of contour No.12 and No.14 where the minimum temperature exceeds $1211 \mathrm{~K}\left(938^{\circ} \mathrm{C}\right)$ contour which is above the $\mathrm{A}_{1}$ transition zone of the $\mathrm{Fe}-\mathrm{C}$ equilibrium diagram [32]. The difference between the computer generated V-shaped contour and the experimental macrograph was also reported by Micallef et al. [4]; the suggested interpretation is that the difference might be due to the variation in plunge depth along the welding line which can result in significant variation in temperature profile. The experimental recordings of the welding parameters included the plunge forces and plunge depth provided by the TWI for FSW of 6- and 8-mm plates of DH36 [TWI FSW data of DH36 steel grade] showed many cases in which there was a drop in the plunge force when the plunge depth drops by parts of a millimetre. Micallef et al. [4] suggested that the variation in the plunge depth is mainly caused by the change of plunge force due to uncontrolled factors such as alternating thicknesses of the workpiece. Wang et al. [33] also observed similar variations in geometry of SZ due to the changes in the plunge depth during their welding experiments. The current model reveals an asymmetry in the temperature profile for all cases studied especially for high welding speeds (W4, W5 and W6). In CFD modelling of FSW of DH36 steel, Micallef et al. [4] reported a certain level of temperature asymmetry for high speed welding; however, they have not reported any localised region in which the temperature can reach to near the solidus temperature under high welding speed. On the other hand, Long et al. [25] reported reaching a melting temperature in 2D-CFD modelling of aluminium alloys FS welded at very high tool rotational speeds exceeding 500 RPM. They argued, using the experimental charts that the reduction in torque when increasing the tool rotational speed was due to a drop in the flow stress. One of the reasons behind this drop in the flow stress is thought to be an increase in the temperature and reaching the melting point in some localised regions. They have also argued that this local melting can lead to an intermittently lubricated contact condition between the tool and the workpiece. Comparison with other model, the current CFD result of the estimate of maximum temperature for W2 $1349 \mathrm{~K}\left(1076{ }^{\circ} \mathrm{C}\right)$ is in good agreement with the results obtained by Toumpis et al. [3] (close to or above $1000^{\circ} \mathrm{C}$ ) for the same steel grade, thickness and welding speed.

However, the distribution of temperature in the SZ is different. This might be due to the different geometry and viscosity ranges applied. The maximum temperature obtained from W5 $1637 \mathrm{~K}$ $\left(1364{ }^{\circ} \mathrm{C}\right)$ is higher than their results $1523 \mathrm{~K}\left(1250{ }^{\circ} \mathrm{C}\right)$ for the same welding condition. Moreover, the distribution of temperature between the advancing and retreating side is also different as here it shows more asymmetry than in their model. 
Fig. 8 Comparing the numerical temperature contours $(\mathrm{K})$ and the experimental steady-state macrograph (IFM) of W8

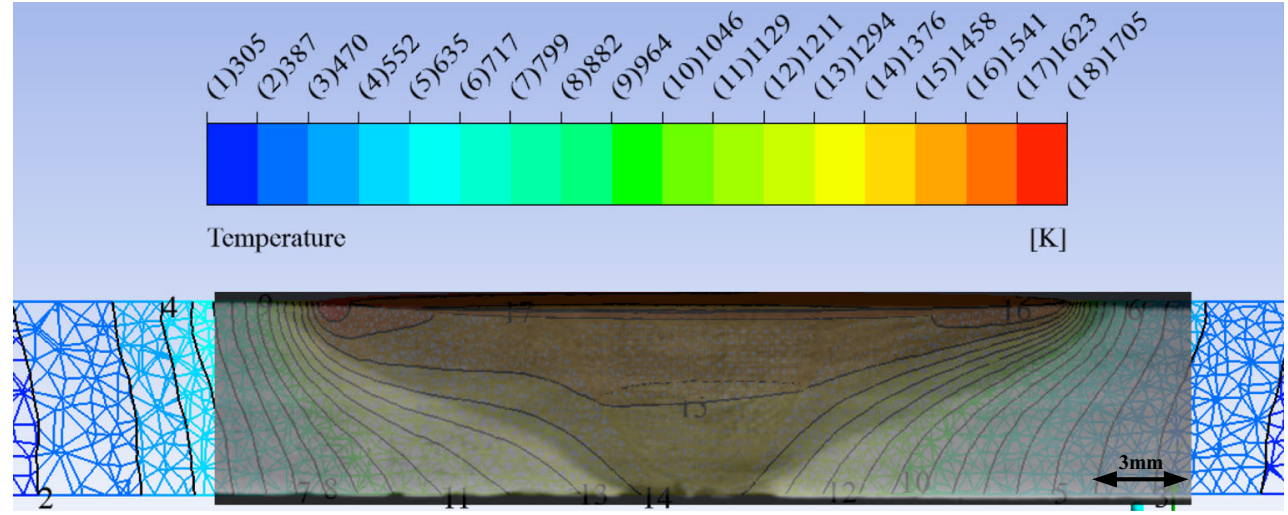

\subsection{Surface temperature of the tool}

Figure 9 shows the temperature distribution around the PCBN tool surfaces for the different welding conditions of $\mathrm{W} 1$ to W6. It is shown from the CFD results that the PCBN-WRe part of the tool experiences different temperatures on the surface during welding; a lower temperature on the leadingretreating side of the tool and higher temperature at the advancing-trailing side. The lowest temperature is on the probe end region at the front of the tool. This was also reported by Micallef et al. [4] where it was interpreted as a viscosity effect. The material at the front of the tool experiences lower plastic deformation because of the higher viscosity while the material at the trailing side experiences higher plastic deformation because of the effect of tool rotation which pushes the material to the back of the tool. Elbanhawy et al. [26] reported the same variation in temperature around the tool surface. As a comparison with the low rotational welding speed, the tool surfaces in the high welding speeds showed less temperature differences between leading and trailing edges due to the short period of time of each complete rotation and also the lowest difference in viscosity between leading and trailing side as will be discussed in the viscosity section. Figure 10 shows that maximum temperature in W6 is located in the shear layer just outside the tool shoulder periphery. This is contrary to previous models which suggest that maximum temperature is always under the tool shoulder. The interpretation for this finding is that as material is heated and pushed around the tool; it reaches a maximum value of strain rate that enables it to gain higher temperature as will be discussed in strain rate and velocity section, later.

\subsection{Strain rate and velocity in the tool/workpiece interface}

Figure 11 shows numerically calculated strain rate contours in the SZ for the 6 different friction stir welding conditions studied W1 through W6-8. It shows that strain rate increases with increasing tool speeds and that this is more dominant in the high welding speeds (W4, W5 and W6-8). Similarly,
Fairchild et al. [34] reported an increase in the strain rate with increasing welding speeds. The maximum value of strain for low welding speeds (W1 and W2) is in the periphery under the tool shoulder; this is because of the maximum relative velocity existing in this region as shown in Fig. 9. However, with increasing rotational and traverse speed, the maximum value of strain rate was in the shear layer just outside the tool periphery. It should be added that there is a difference in strain rate values between the advancing and retreating sides especially for the high traverse speeds (W4, W5, W6-8). This difference in strain rate values may have resulted from an increased difference in the relative velocity between the advancing and retreating sides of the tool. It is shown that strain rate can reach to a value of $1000 \mathrm{~s}^{-1}$ at the tool shoulder periphery especially for high tool speeds (W5 and W6) as a result of fully sticking conditions. The strain rate values for modelling the same steel grade and welding conditions were reported with lower values when the slipping conditions appear during the process [18]. Figure 12 shows the distribution of relative velocity in the contact surface of the tool/workpiece interface for the studied cases. For the low and medium welding speed the strain rate distribution is nearly symmetrical. The lowest value of strain rate can be found in the probe end as a result of lower relative velocity. The asymmetry in relative velocity which is mainly coming from the variation in the term "Usin $\theta$ " described in Eq. 20 and shown in Fig. 12 is the main contributor to the asymmetry in the temperature, viscosity and strain rate. This asymmetry consequently affects the mechanism of heat generation. Figures 11 and 12 also show that the difference between advancing and retreating sides in strain rate and velocity fields for all studied cases near the probe end is small and thus can almost produce symmetrical SZ at that location. This is in agreement with Nandan et al. [2] where they argued that this is due to the rapid recirculation of plastic material which itself results in the local temperature distribution not varying significantly at the probe end. Comparing Fig. 12 W1 through W6 shows that velocity is more sensitive to tool rotational speed where increasing tool rotational speed resulted in an increased relative velocity. 
Fig. 9 The temperature $\left({ }^{\circ} \mathrm{C}\right)$ contours around the PCBN tool surfaces for six different welding conditions; (W1 to W6-8)

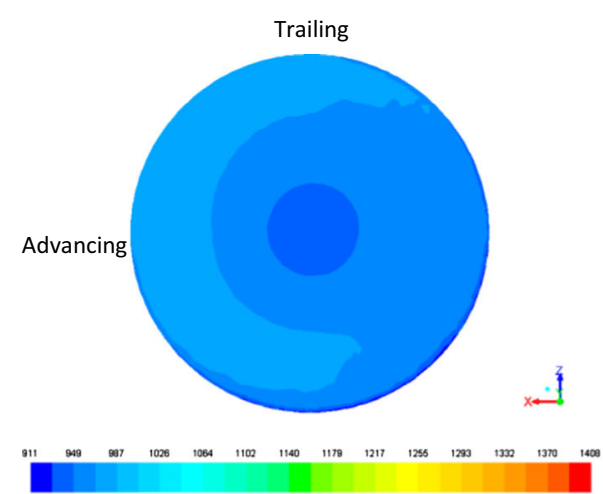

W1

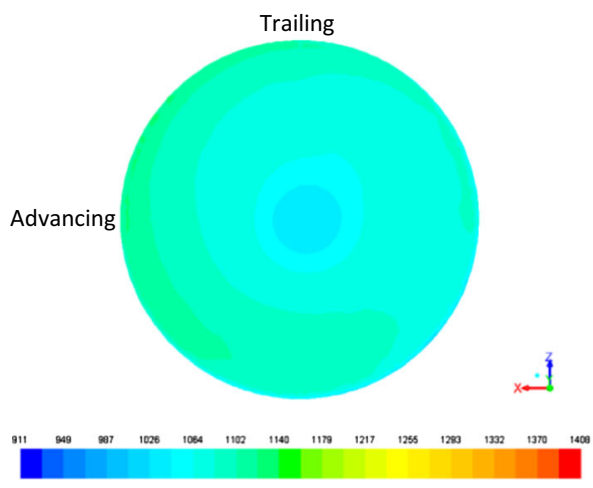

W3

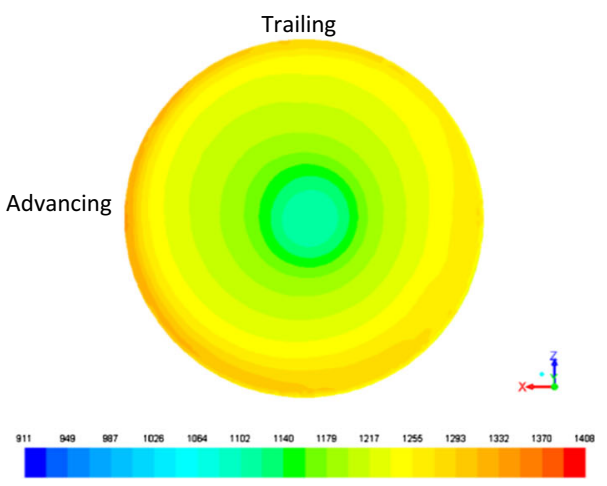

W5

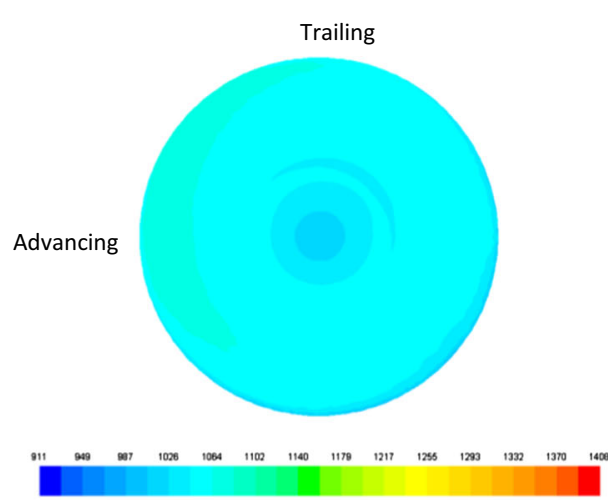

W2

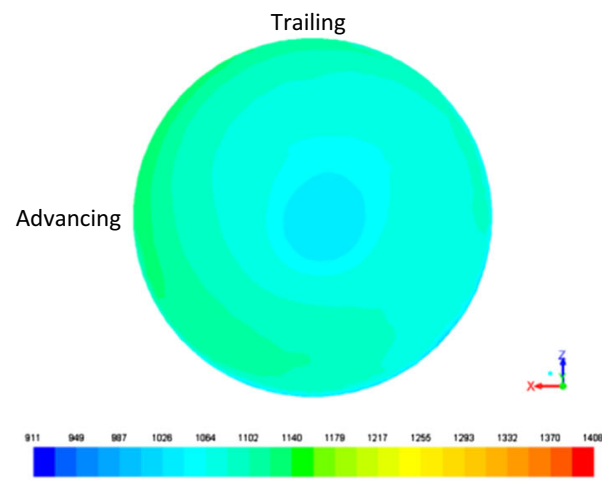

W4

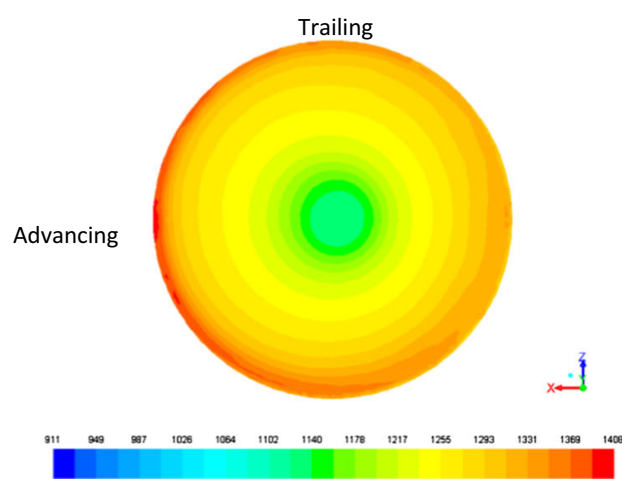

W6-8

\subsection{Local pressure distribution}

It is noticed from Fig. 13 that there is a difference in local pressure values between the advancing and retreating sides and the difference is increased with increasing tool speeds. The retreating side showed a drop in pressure which can cause a consolidation defect [33]. This type of defect was reported in the retreating side as a result of insufficient internal pressure which in turn results in a drop in the forging forces which are required to keep the material consolidation [33]. The current model suggests that more defects can be created in the weld where there is a greater difference in local pressure between advancing and retreating sides. The differences in local pressure increased with increasing traverse speed even when the tool rotational speed was increasing as shown in Fig. 13, W4, W5 and W6. So it is expected that more defects can be found in the high traversing welds even with increasing the tool rotational speeds. For W4, W5 and W6 the local pressure contours also showed a significant change in the end of probe side at the advancing side, this inhomogeneity in pressure at that location can increase the possibility of void or crack initiation. The pressure change in this specific location can be the results of higher traversing speed which may cause a lack of material flow as will be discussed in material flow section. Nandan et al. [35] found that there is a big difference in pressure at the lower portion of the workpiece due to the low 


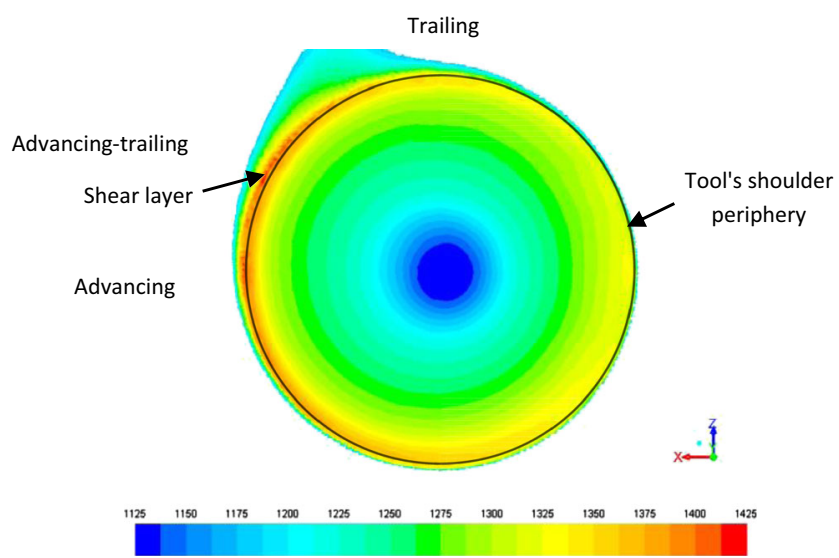

Fig. 10 temperature $\left({ }^{\circ} \mathrm{C}\right)$ distribution on the tool surface and shear layer (TMAZ) for samples W6-8 showing the maximum temperature for high speed welds (550RPM)

temperature and strain rate which cause a higher flow stress and thus a higher pressure required to fulfil the material flow. This interesting result needs more investigation. W1 and W2 show more homogeneous pressure distribution between advancing and retreating sides, so defect formation is expected to be less. In all cases it is noticed that pressure is increasing with tool rotation and traverse speeds. The higher pressure shown in the advancing side rather than the retreating side is the results of formation of stagnant zone which needs more pressure to achieve material flow.

Figure 14 shows the local pressure distribution in the tool/workpiece interface surface of W5 where the pressure in front of the tool is higher than in the trailing edge. The difference in pressure values between leading and trailing edges is very high towards the tool periphery. Morisada et al. [36] interpreted the high pressure value in front of the tool shoulder rather than the shoulder back as the results of tool traversing.

\subsection{Parent material flow around the tool}

It is noted from Fig. 15, W2 and W6 as study cases of low and high welding speeds respectively that material flows around the tool with asymmetric circular shape especially for the high welding traverse speed. The flow is deflected at the retreating side in the direction of rotation. Previous experimental work by Schmidt et al. [37] carried out on aluminium showed the same results of material flow, where marker foils of copper flowed around the tool, broken into pieces then reverted around the retreating side in the same direction of rotation. Morisada et al. [38] used a W tracer with the aid of an XR transmission system to monitor the material flow during FSW of aluminium A1050 and low carbon steel. They found that in $\mathrm{Al}$ the $\mathrm{W}$ tracer can rotate many times around the probe, whereas, in steel the tracer moved along the rotating probe, passed through the retreating side and stopped at the back of the probe. They also found that the tracer velocity in steel was smaller than those of $\mathrm{Al}$ as steel is more resistance to material flow. They reported that the shape of the stirred zone in steel was changed because of the formation of a stagnant zone at the advancing side. Because of the relatively high deformation resistance behaviour of steel, they suggested a low tool
Fig. 11 The distribution of strain rate $\left(\mathrm{s}^{-1}\right)$ in the contact surface of the tool/workpiece for the 6 different studied conditions W1 through W6-8

$$
\text { Advancing }
$$
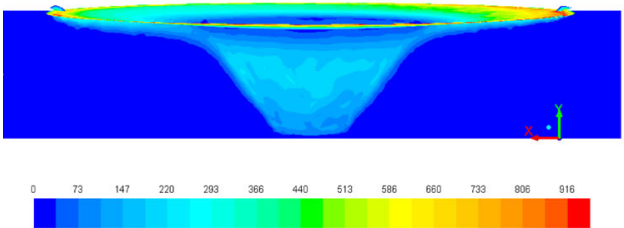

W1
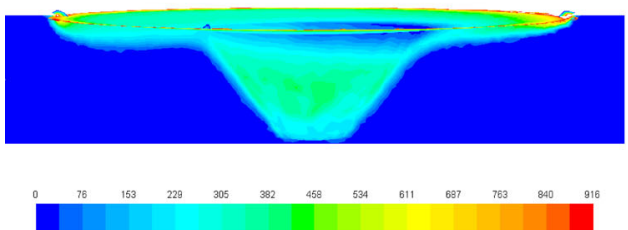

W3

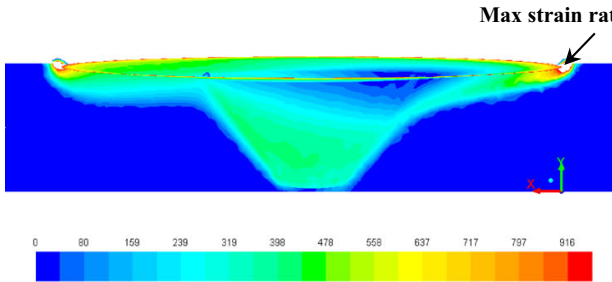

W5

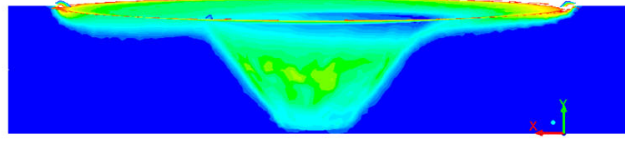

W4

Advancing
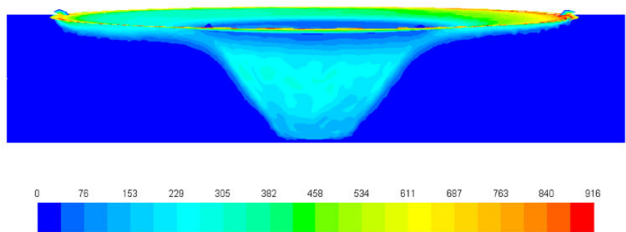

W2
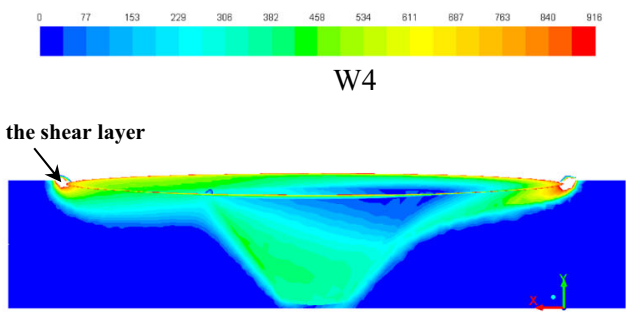

W6 
Fig. 12 The distribution of relative velocity $(\mathrm{m} / \mathrm{s})$ between the tool/workpiece interfaces for the six different studied conditions W1 through W6-8
Advancing

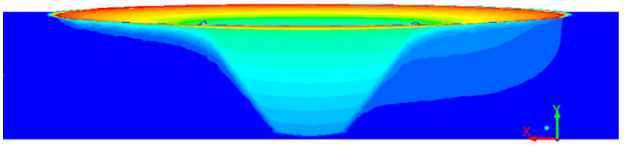

(no

$\begin{array}{llllllllllll}0.16 & 0.032 & 0.048 & 0.084 & 0.080 & 0.096 & 0.112 & 0.128 & 0.43 & 0.159 & 0.175 & 0.189\end{array}$

W1
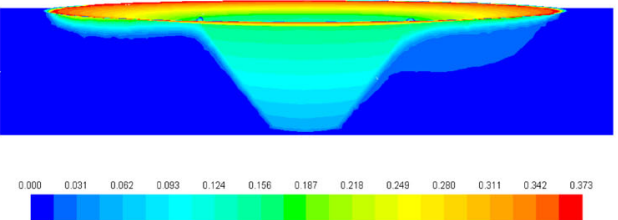

W3
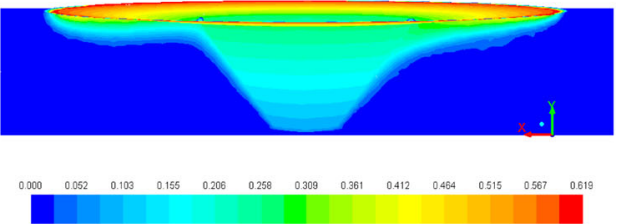

W5
Advancing
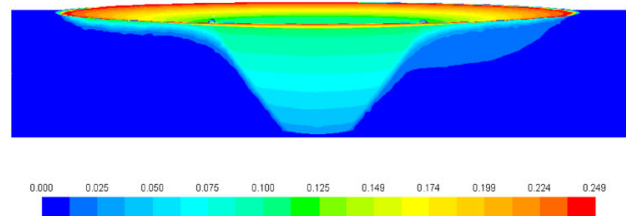

W2

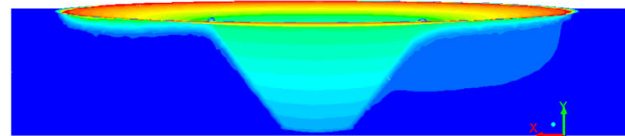

W4

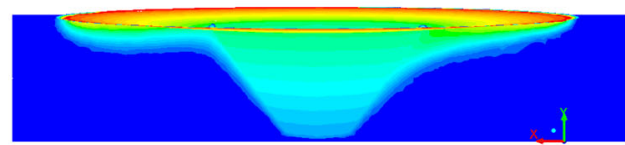

W6 rotational speed to achieve a uniform flow zone and optimal FSW conditions. In Fig. 16, W2 and W6, the maximum flow was noted at the periphery of the tool shoulder of low and high welding speeds, respectively. The flow is decreased towards the probe end. Figures 15 and 16 show that the material adjacent to the tool periphery (shear layer) is highly affected by the tool rotation so it gained velocity. The shear layer rotation means that this region experienced plastic deformation, a high strain rate, high temperature and thus low viscosity. This region forms together with the main stirred zone the final shape of the SZ. It is worth noting that the size of the shear layer increases with increasing tool rotational speed. Figure 15 W2 shows less thickness of shear layer compare to W6 due to lower tool rotational speed. The shear layer size is larger
Fig. 13 The distribution of local pressure $(\mathrm{Pa})$ between advancing and retreating sides

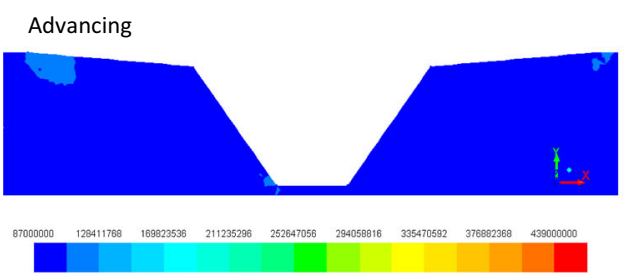

W1
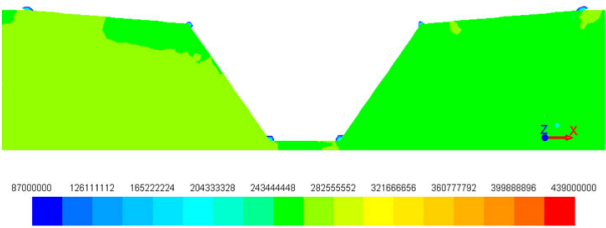

W3

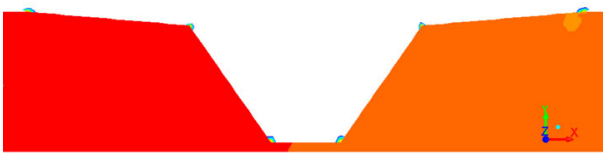

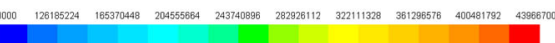
W5
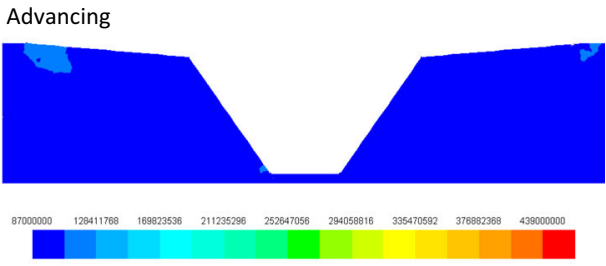

W2
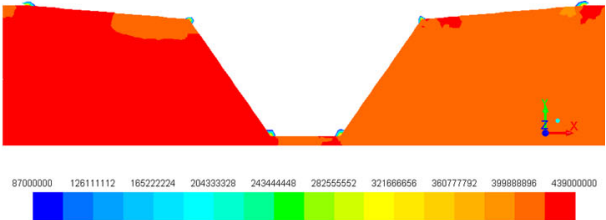

W4

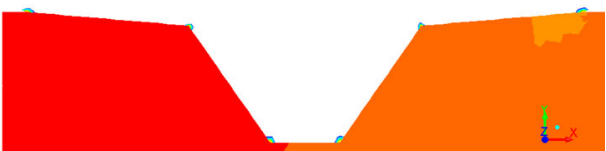

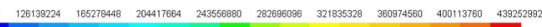
W6 


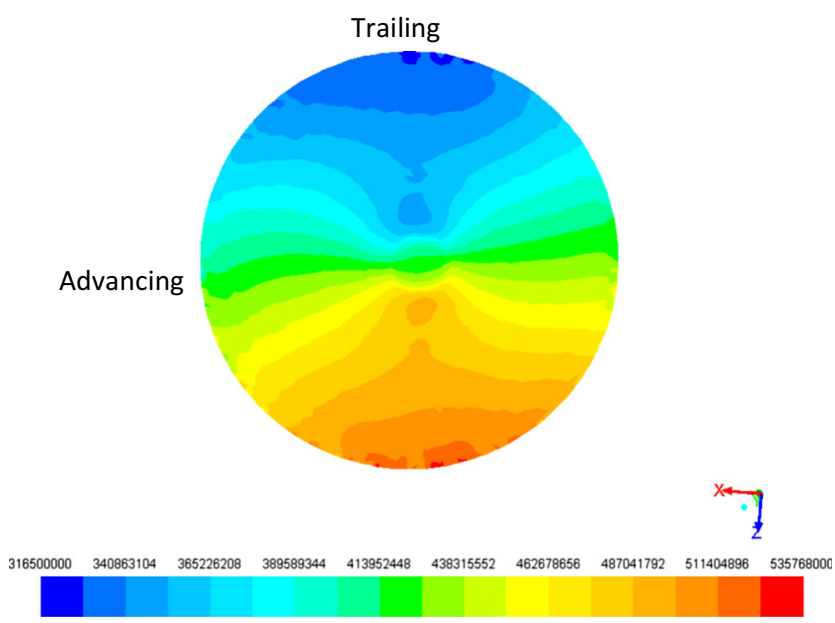

Fig. 14 The local pressure $(\mathrm{Pa})$ distribution between the leading and trailing side of tool surface of W5

around the shoulder but decrease towards the probe. As mentioned previously in the discussion of velocity and strain rate section that there is a stagnant zone that can cause a wormhole defects. From Fig. 15, it is shown that this region is located between the stream lines that show a rotation without flow reversal and the adjacent stream lines that show a reversal in flow on the advancing side. This region showed the minimum value of velocity around the tool ranged from $0.0024-0.1 \mathrm{~m} / \mathrm{s}$ for W6. The stagnant region as mapped in 3D shown in Fig. 16, W6 is approximately from the mid thickness of the workpiece to the shoulder of the tool. The previous work found in $[2,5,22]$ reported the wormhole defect in the same region of interest and they found that the occurrence of this defect increased as traverse speed increased due to inadequate material flow. Morisada et al. [38] also suggested that the formation of a stagnant zone can lead to a defect in the SZ and that uniform material flow for steel is only achieved at low traverse speed. They interpreted the formation of a stagnant zone on the advancing side as being caused by a low heat input due to high traverse speed. For low traverse speed welds (Fig. $15 \mathrm{~W} 2$ ) it is shown that the flow is nearly symmetrical

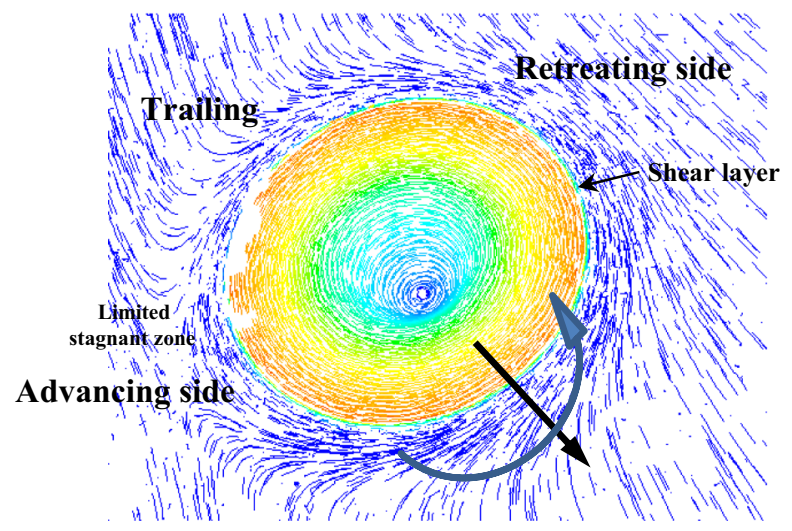

(a) W2 and the stagnant zone is limited, this in turn caused nearly symmetrical velocity, strain rate and temperature fields and therefore created fewer defects. To demonstrate the importance of material flow as a main source of heating in FSW process, the heat transfer by convection to that by conduction represented by Peclet $\left(\mathrm{P}_{\mathrm{e}}\right)$ number is calculated as follows [2]:

$\mathrm{Pe}=\frac{\rho U_{c} C_{p} L_{c}}{k}$

$\mathrm{U}_{\mathrm{c}}$ is the characteristic velocity $=0.685 \mathrm{~m} / \mathrm{s}$ for $\mathrm{W} 6-8$ (see Fig. $10 \mathrm{~W} 6), \mathrm{L}_{\mathrm{c}}$ is the characteristic length which represent the shear layer thickness taken from infinite focus microscope IFM experiments and $=0.01 \mathrm{~m}$ as average. So Pe will be equal to 561 which indicates that material flow plays a major role in heat transfer during the FSW process of steel especially under the tool shoulder. The importance of material flow in heat transfer during the FSW process was also reported in [14] for modelling aluminium AA5083-H131 and they found that Pe number was still high even when the thermal conductivity is very high.

\subsection{Estimating the SZ from viscosity change}

It is shown from Fig. 17, W1 through W6 that viscosity decreases with increasing tool rotational speed, this decrease can encourage the layers of the material in contact with the tool to rotate with a specific velocity. The high values of viscosity just after this region will prevent material from moving due to the lack of plastic flow and thus defining the limits of the SZ. It is also worth noting that the calculated temperature around the tool was not enough to markedly decrease the viscosity and allow the material to flow. The strain rate is probably playing a significant role in decreasing the value of viscosity. Viscosity is inversely proportional to strain rate and temperature, so considering the CFD results of temperature and strain rate which show a decrease in temperature and strain rate towards

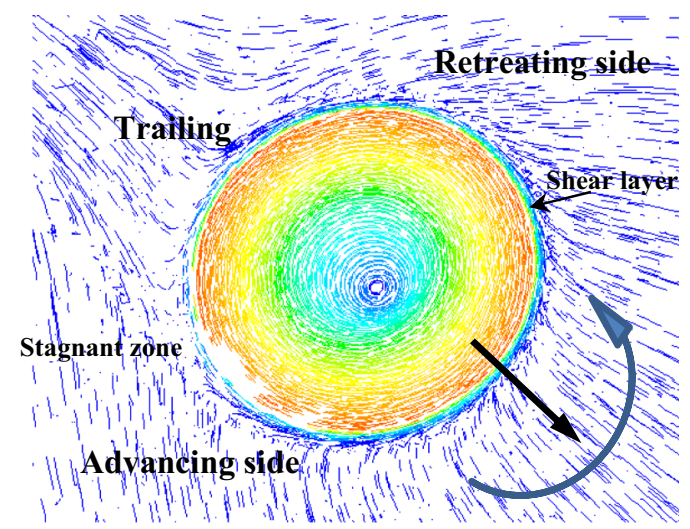

(b) W6

Fig. 15 Material flow path lines in and around the tool/workpiece contact region a W2 and $\mathbf{b}$ W5 (3D top view) 


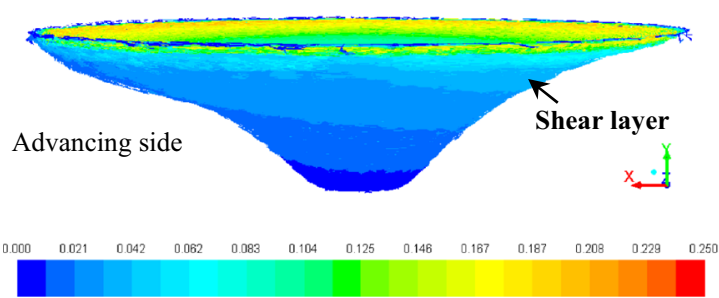

W2

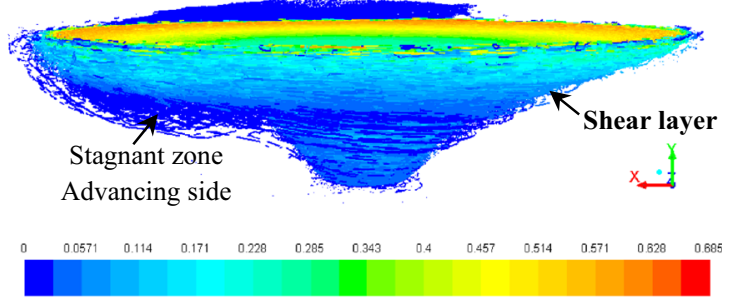

W6

Fig. 16 The material flow coloured by local velocity $(\mathrm{m} / \mathrm{s})$ for a high welding speeds and $\mathbf{b}$ low welding speeds (3D advancing-retreating sides)

Fig. 17 Viscosity (Pa.s) distribution around the tool/workpiece

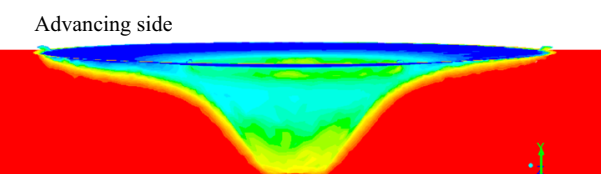

W1

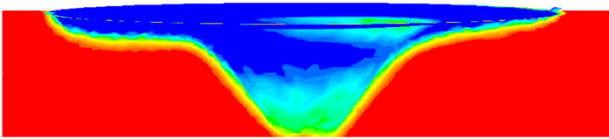

W3

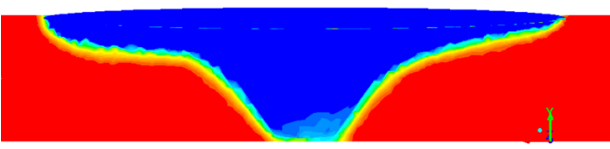

W5
Advancing side

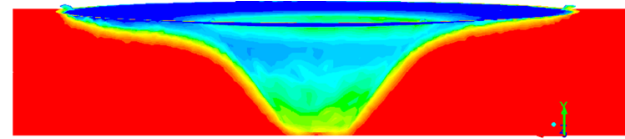

W2

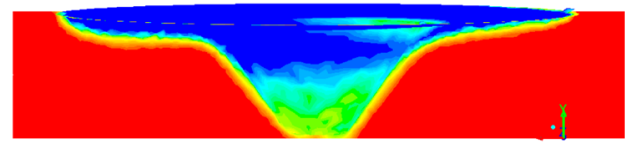

W4

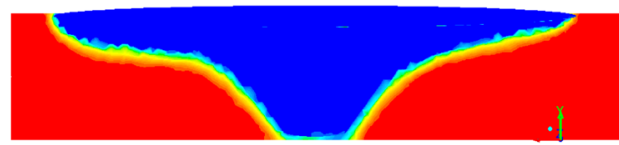

W6-8

$6 e+04 \quad 1 e+06 \quad 2 e+06 \quad 3 e+06 \quad 4 e+06 \quad 5 e+06 \quad 6 e+06 \quad 7 e+06 \quad 8 e+06 \quad 9 e+06 \quad 1 e+07$

the probe end, it is expected that viscosity will show an increase towards the probe end and this is the main reason for the V-shaped geometry around the contact region. Nandan et al. 2007 [2] reported the same viscosity increase towards the probe end. It can also be shown that increasing the traverse speed in W4 caused an increase in viscosity at the probe side bottom as compare to W3 which shows a lower value of viscosity although the tool rotational speed was lower. This can be attributed to the less heat input towards the probe in W4. From the viscosity, strain rate and velocity and temperature contour, it can be inferred that the tool shoulder and probe side play the most important role in generating the heat required for welding, whereas, the probe end plays an insignificant role in stirring the material in contact. It is also shown from Fig. 17 that the most affected zone by stirring is between the shoulder and probe side due to the combination of these two parts of the tool. Figure 18 shows a comparison between the CFD viscosity profile results and the macrograph of the SZ (marked by the red line) of W8 which shows an acceptable representation of the SZ with some slight
Fig. 18 Comparison of CFD viscosity-macrograph of W8

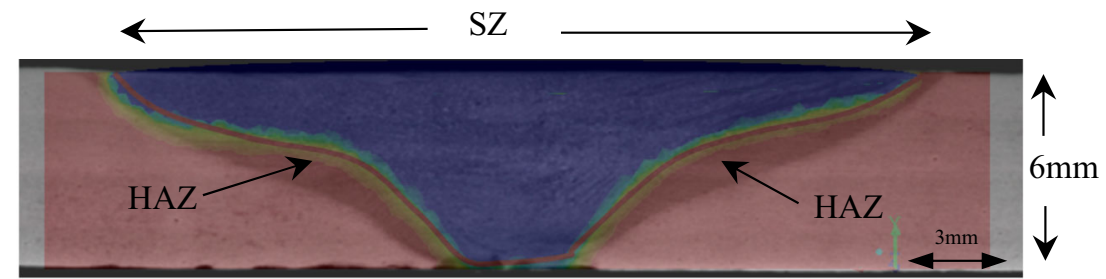

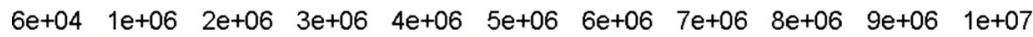

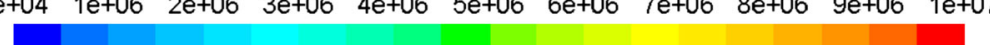


Fig. 19 Local values of viscosity (Pa.s) on the top surface of the SZ for low and high welding speeds (W2 and W6), respectively
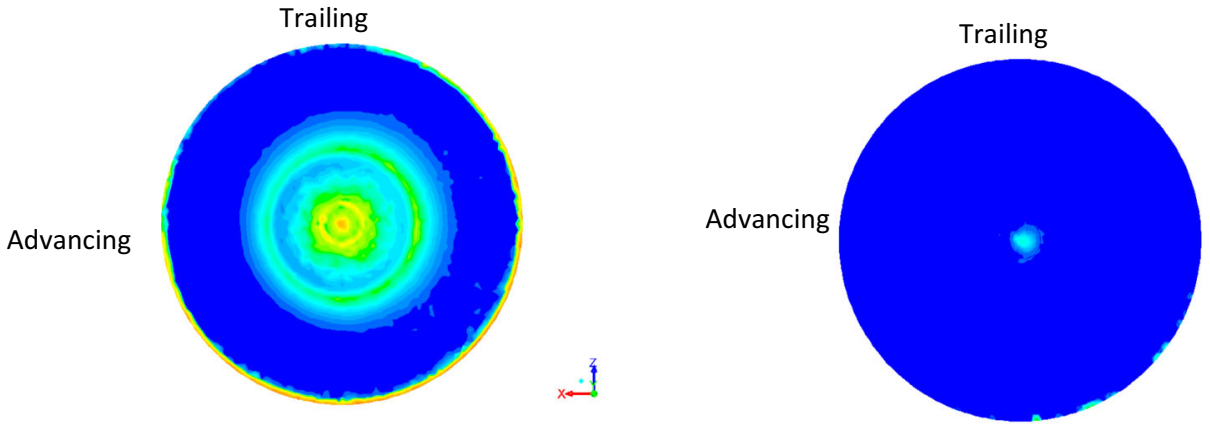

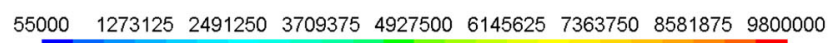

\section{W2}

W6 differences which may be caused by variation in plunge depth as discussed previously. Figure 18 shows a top view of the local viscosity for the SZ of W2 and W6 low and high welding speeds respectively. From Figs. 17 and 19, it can be confirmed
Fig. 20 Predicted shear stress

(Pa) contours on the tool surface (W1-W6)

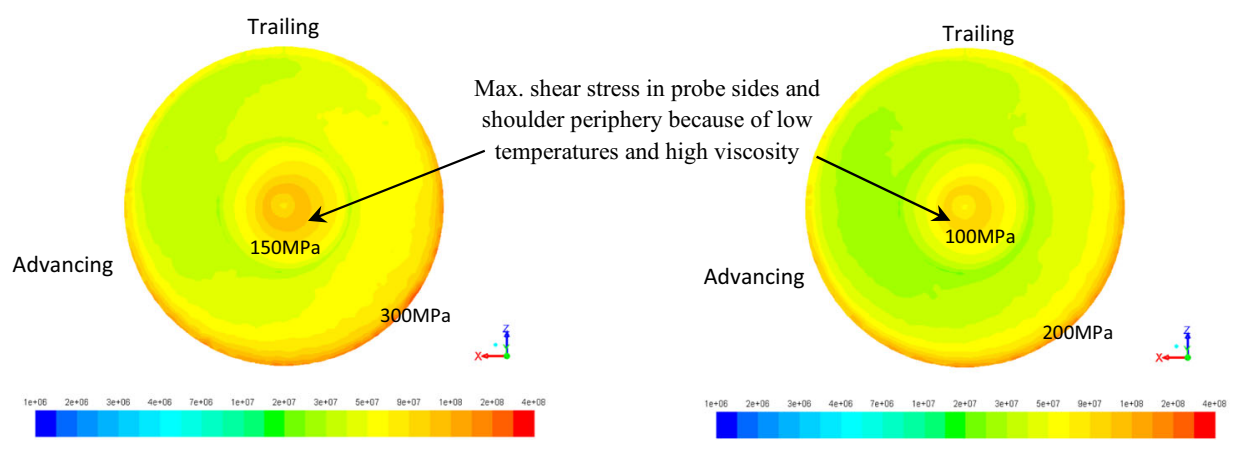

W1

W2
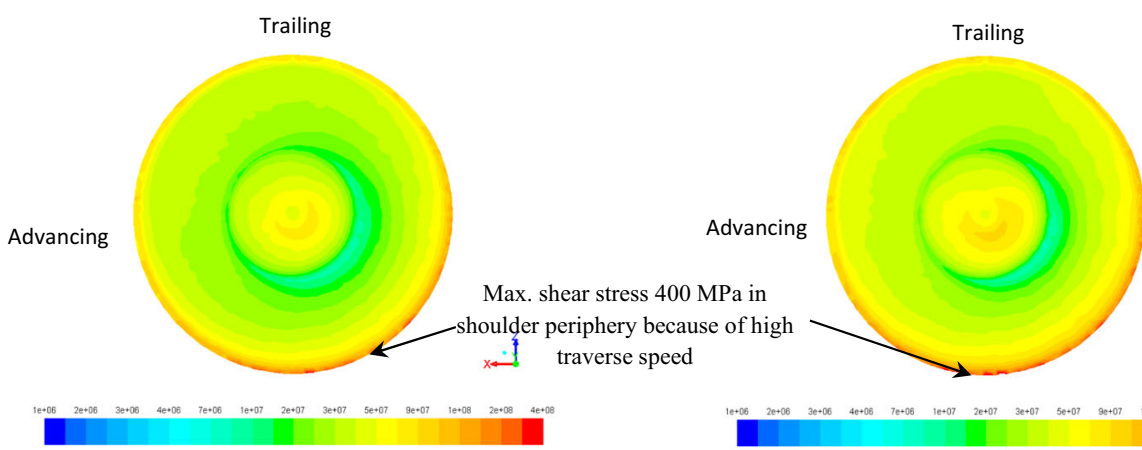

W3

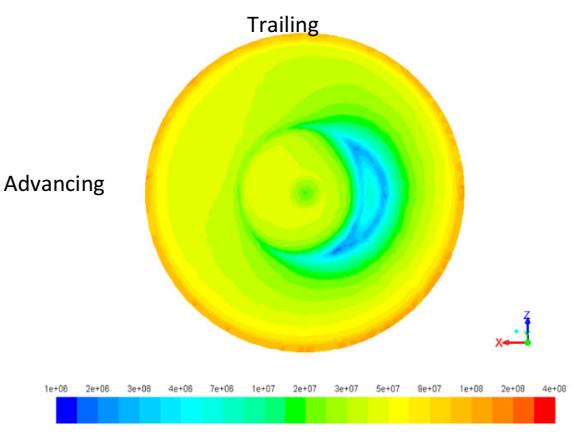

W5

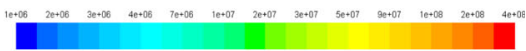

W4

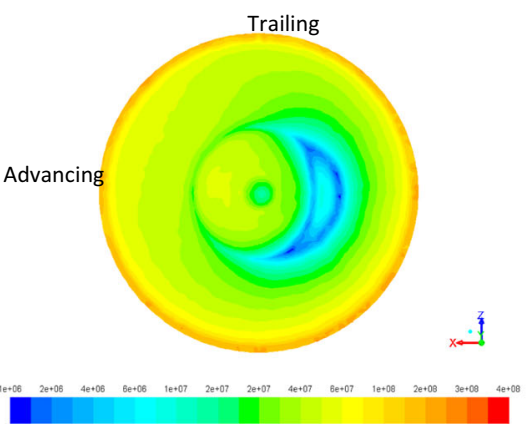

W6 
that the value of viscosity in which material can flow for all cases under study is ranged from 55,000 to $9.8 \times 10^{6} \mathrm{~Pa}$.s. The cutoff viscosity value is $9.8 \times 10^{6} \mathrm{~Pa}$.s which is in good agreement with the previous work carried out on steel extrusion [2].

\subsection{Shear stress on the surface of the tool}

The maximum shear stress predicted by the model for low and medium welding speeds (W1, W2, W3 and W4) as shown in Fig. 20 is associated with the leading edge of the tool towards the retreating side; which coincides with the prediction for the minimum temperature on the tool (see Fig. 7). The reason for this is the tool surface leading edge is in contact with higher degrees of viscosity than the trailing edge as shown in Fig. 18 W2. High tool rotational speeds W5 and W6 show a nearly symmetrical shear stress distribution on the tool shoulder periphery. For constant traverse speeds (W4, W5, and W6), the model predicts that the shear stress will decrease with increasing tool rotational speed because of the associated increase in temperature. The model further predicts that the probe sides is subjected to a higher shear stress at lower tool rotational speed, as shown for W1 and W2 in Fig. 20 because it experiences lower temperatures and higher viscosity (Fig. 9 and Fig. 17, respectively). W4 predicts an increase in shear stress at the shoulder periphery and probe side leading edge compared to W3 because of the higher traverse speed. From the previous discussion, it is recommended to increase the tool rotational speed and decrease the traverse speed in order to reduce the tool wear especially at the probe side and shoulder periphery.

\section{Conclusion}

From the preceding discussion, the following can be concluded:

CFD modelling of FSW of DH36 steel shows that the maximum temperatures for low and medium welding speeds are located under the tool shoulder.

For high rotational speeds (with traverse speed of $400 \mathrm{~mm} /$ min) W5 and W6, higher temperatures existed in the shear layer just out the tool shoulder periphery.

The prediction from the CFD model indicates that compared to tool traverse speed, tool rotational speed plays a significant role in generating heat in the tool/workpiece interface. On the other hand, increasing traverse speed can significantly cause an increase in the cooling rate.

The model predicts that the FSW tool has experienced a range of temperatures across its surface during FSW, a maximum temperature on the advancing-trailing side and a lower temperature on the leading-retreating side. The minimum temperature was found at the probe end.
The CFD model predicts that strain rate increases with increasing tool rotational speed; it also showed an increase with increasing traverse speed.

Local pressure between the tool and the workpiece was asymmetrical between the advancing and retreating sides, the difference in pressure value increases with increasing traverse speed.

It is proposed that the increase in pressure difference between the adjacent regions especially near the probe end could be the cause of weld defects. High traverse speed may create a stagnant zone which in turn can become a source of defects such as wormholes as results of the lack in material flowing.

The shape and dimensions of the stirred zone has been estimated effectively from the viscosity contours in the CFD model. The SZ size increased with the increase in tool rotational speed. This was because of a decrease in viscosity which in turn encourages steel layers to rotate.

Viscosity increases with increasing traverse speed especially on the probe side.

The tool shoulder surface experiences high shear stress at low tool rotational speeds.

The shear stress on the leading-retreating side was greater than on the advancing-trailing side because of the temperature difference which was lower at the leading-retreating side.

The tool probe sides experience the maximum shear stress at lower tool rotational speeds. The shear stress was also increased with increasing the weld traverse speed (e.g. W4).

Acknowledgements The authors would like to thank the TWI company for providing samples and data of FSW DH36 steel. The author also thanks the ministry of higher education/Iraq for funding the study. The authors are grateful for Ali Riza, the $\mathrm{PhD}$ student for his support regarding CFD modelling.

Open Access This article is distributed under the terms of the Creative Commons Attribution 4.0 International License (http:// creativecommons.org/licenses/by/4.0/), which permits unrestricted use, distribution, and reproduction in any medium, provided you give appropriate credit to the original author(s) and the source, provide a link to the Creative Commons license, and indicate if changes were made.

\section{References}

1. Xiaocong H, Fengshou G, Andrew B (2014) A review of numerical analysis of friction stir welding. Prog Mater Sci 65:1-66

2. Nandan R, Roy GG, Lienert TJ, Debroy T (2007) Threedimensional heat and material flow during friction stir welding of mild steel. Acta Mater 55(3):883-895

3. Toumpis AI, Gallawi A, Arbaoui L, Poletz N (2014) Thermomechanical deformation behaviour of DH36 steel during friction stir welding by experimental validation and modelling. Sci Technol Weld Join 19(8):653-663

4. Micallef D, Camilleri D, Toumpis A, Galloway A, \& Arbaoui L (2015) Local heat generation and material flow in friction stir welding of mild steel assemblies. J Materials: Design and Applications, $0(0)(0), 1-17$ 
5. Enkhsaikhan B, Edward C (2009) Detecting wormholes in friction stir welds from welding feedback data, Midwest instruction and computing symposium. South Dakota, USA

6. Toumpis A, Gallawi A, Cater S, McPherson N (2014) Development of a process envelope for friction stir welding of DH36 steel — a step change. Mater Des 62:64-75

7. Stevenson R, Toumpis A, Galloway A (2015) Defect tolerance of friction stir welds in DH36 steel. Material and design 87:701-711

8. Toumpis AI, Gallawi A, Molter L, Polezhayeva H (2015) Systematic investigation of the fatigue performance of a friction stir welded low alloy steel. Mater Des 80:116-128

9. Lenard J, Pietrzyk M, Cser L (1999) Mathematical and physical simulation of the properties of hot rolled products. Elsevier, Amsterdam, pp 1-10

10. Megastir (2013) Friction Stir Welding of high melting temperature materials .Online resource

11. Endo R, Shima M, Susa M (2010) Thermal-conductivity measurements and predictions for $\mathrm{Ni}-\mathrm{Cr}$ solid solution alloys. Int $\mathrm{J}$ Thermophys 31:1991-2003

12. Atharifar H, Lin D, Kovacevic R (2009) Numerical and experimental investigations on the loads carried by the tool during friction stir welding. J Mater Eng Perform 18(4):339-350

13. Jacquin D, de Meester B, Simar A, Deloison D, Montheillet F, Desrayaud C (2011) A simple Eulerian thermomechanical modeling of friction stir welding. J Mater Process Technol 211(1):57-65

14. Grujicic M, Arakere G, Yalavarth HV, He CF, Yen C-F, Cheeseman BA (2010) Modeling of AA5083 material-microstructure evolution during butt friction-stir welding. J Mater Eng Perform 19(5):672684

15. Schmidt H (2004) Hattel J and wert J,2004, an analytical model for the heat generation in friction stir welding. Modelling Simul Mater Sci Eng 12:143-157

16. Cox C, Lammlein D, Strauss A, Cook G (2010) Modeling the control of an elevated tool temperature and the affects on axial force during friction stir welding. Mater Manuf Process 25:1278-1282

17. Hasan AF, Bennett CJ, Shipway PH (2015) A numerical comparison of the flow behaviour in friction stir welding (FSW) using unworn and worn tool geometries. Mater Des 87:1037-1046

18. Al-moussawi M, Smith AJ, Young A, Cater S and Faraji M (2016) An advanced numerical model of friction stir welding of DH36 steel, 11th Int. Symp. FSW, TWI Granta Park Cambridge, UK

19. Cho H, Kimd D, Hong S, Jeong Y, Lee K, Cho Y, Kang S, Han H (2015) Three-dimensional numerical model considering phase transformation in friction stir welding of steel. Metall Mater Trans A 46A:6040-6051

20. Arora A, Nandan R, Reynold AP, DebRoya T (2009) Torque, power requirement and stir zone geometry in friction stir welding through modelling and experiments. Scr Mater 60(1):13-16

21. Darvazi AR, Iranmanesh M (2014) Thermal modeling of friction stir welding of stainless steel $304 \mathrm{~L}$. Int J Adv Manuf Technol 75(912):1299-1307
22. Pal S, Phaniraj MP (2015) Determination of heat partition between tool and workpiece during FSW of SS304 using 3D CFD modelling. J Mater Process Technol 222:280-286

23. Bergman TL, Incropera FP, DeWitt David P, Lavine AS (2011) Fundamentals of heat and mass transfer, 7th E edn. John Wiley and sons, USA

24. Khandkar MZH, Khan JA, Reynolds AP (2003) Prediction of temperature distribution and thermal history during friction stir welding: input torque based model. Sci Technol Weld Join 8(3): 165-174

25. Long T, Tang W, Reynolds AP (2007) Process response parameter relationships in aluminium alloy friction stir welds. Sci Technol Weld Join 12(4):311-317

26. Elbanhawy A, Chevallier E, Domin K (2013) Numerical investigation of friction stir welding of high temperature materials. NAFEMS world congress, Salzburg

27. Besharati-Givi MK and Asadi P (2014) Advances in friction-stir welding and processing, a volume in woodhead publishing series in welding and other joining technologies, ScienceDirect

28. Fehrenbacher A, Schmale JR, Zinn MR, Pfefferkorn FE (2014) Measurement of tool-workpiece Interface temperature distribution in friction stir welding. J Manuf Sci Eng 136(2):21009

29. Yang KY, Dong H, Kou S (2008) Liquation tendency and liquidfilm formation in friction stir spot welding. Weld J 87:202-211

30. Colegrove P, Shercliff (2005) 3-dimensional CFD modelling of flow round a threaded friction stir welding tool profile, H. J Mater Process Technol 169:320-327

31. Smith AJ, AL-Moussawi M, Young AE, Cater S and Faraji M (2016). Modelling of friction stir welding of 304 stainless steel. In: European Simulation and Modelling Conference, Univ. of Las Palmas, 26-28th October 2016

32. Leonard ES (1999) Light microscopy of carbon steel, ASM International $\odot$, USA

33. Wang H, Colegrove PA, dos Santos J (2013) Hybrid modelling of 7449-T7 aluminium alloy friction stir welded joints. Sci Technol Weld Join 18:147-153

34. Fairchild D, Kumar A , Ford S, Nissley N (2009) Research concerning the friction stir welding of linepipe steels, Trends in welding research, Proceedings of the 8 th International Conference, pp371-380

35. Nandan R, Lienert TJ, Debroy T (2008) Toward reliable calculations of heat and plastic flow during friction stir welding of Ti-6Al$4 \mathrm{~V}$ alloy. Int J Mat Res 99(4):434-444

36. Morisada Y, Fujii H, Kawahito Y, Nakata K, Tanaka M (2011) 2011, three-dimensional visualization of material flow during friction stir welding by two pairs of X-ray transmission systems. Scr Mater 65:1085-1088

37. Schmidt HNB, Dickerson TL, Hattel JH (2006) Material flow in butt friction stir welds in AA2024-T3. Acta Mater 54:1199-1209

38. Morisada Yet al (2014) Three-dimensional visualization of material flow during friction stir welding of steel and aluminum. J Mater Eng Perform 23(11):4143-4147 